\title{
Projeto de células de manufatura com o auxílio de coloração em grafos
}

\author{
Edsandra Mara de Azevedo
}

Orientador:

Prof. Dr. José Francisco Ferreira Ribeiro

Dissertação apresentada ao Instituto de Ciências Matemáticas e de Computação ICMC-USP, como parte dos requisitos para obtenção do titulo de Mestre em Ciências de Computação e Matemática Computacional.

\author{
USP - São Carlos \\ Deze mbro/2002
}

\section{"VERSÃO REVISADA APÓS A DEFESA"}

Data da Defesa:

$11 / 11 / 2002$

Visto do Orientador: 
Scja lá o que você possa fazer, ou sonhe que pode, comece.

A ousadia tem gênio, poder e magia dentro de si. Comece agora.

Goethe 
Aos meus pais Edival e Elenir 


\section{Agradecimentos}

Primeiramente, um agradecimento especial ao Prof. Dr. José Francisco Ferreira Ribeiro, meu orientador, não só pela dedicação, cuidado e paciência, mas também pela amizade e palavras de encorajamento nas horas mais adversas.

Aos professores do ICMC - USP pelos ensinamentos e boa vontade com que me receberam.

À minha família, pelo apoio e compreensão, e de maneira mais especial à minha mãe, Elenir e ao meu pai Edival que se sacrificaram muitas vezes para que eu chegasse até aqui.

Aos meus irmãos, Ednéia e Edivandro; ao meu cunhado, Décio e à minha cunhada Andréia pelo carinho, ajuda e conselhos dados.

Ao meu namorado, Helton, pelo companheirismo, compreensão, apoio, ensinamentos e dedicação em todos os momentos.

Aos meu amigos: Lee, Claudia, Pepe, Sônia, Homero, Gecirlei, George e Fabrizio por compartilharem tantas dificuldades e alegrias.

Às amigas: Gessi Cristina, Claudia Orlandini, Fátima e Ana Christina pelas palavras de encorajamento e pelo apoio nos momentos mais dificeis.

Às secretárias, Beth, Laura e Ana Paula, e aos funcionários da gráfica pela simpatia e eficiência que sempre me atenderam.

À Direção do Instituto de Ciências Matemáticas e de Computação por ter me acolhido tão generosamente nesta Instituição e fornecido os meios para que este trabalho tivesse bom encaminhamento.

Ao CNPq pelo suporte financeiro que possibilitou a realização deste trabalho.

Peço desculpas às pessoas que contribuíram direta ou indiretamente durante o Programa de Mestrado e que não foram expressamente citadas. Agradeço a todos.

Finalmente agradeço a Deus pela força que tem me dado e peço a Ele que abençoe a todos! 


\section{Resumo}

Nesta dissertação é apresentado um método para o projeto de células de manufatura baseado em coloração em grafos. O método proposto calcula as dissimilaridades entre as peças e organiza o sistema de produção em famílias de peças e grupos de máquinas. Um grafo correspondente ao sistema de produção é gerado e um algoritmo de coloração acionado para obter um número de cores igual ao número desejado de células. O programa correspondente foi escrito em linguagem Delphi e está implementado em microcomputador. Os resultados obtidos sobre vários exemplos da literatura são equivalentes ou melhores do que aqueles propostos até o presente momento, em termos do número de movimentos inter-células e da dimensão das células. 


\begin{abstract}
A method for cellular manufacturing is presented in this paper. The proposed method computes the dissimilarities between parts and organizes the production system in partfamilies and group-machines. A graph corresponding to the production system is generated and a coloring algorithm is activated in order to obtain a number of cells equal to the desired number of cells. The corresponding program was written in Language Delphi and runs on a microcomputer. The results obtained on several examples found in the literature are consistently equivalent to or even better than those hitherto proposed, in terms of intercell moves and dimensions of the cells.
\end{abstract}


Capítulo 1. Projeto de Células de Manufatura 4

1.1. Tecnologia de Grupo $\quad 4$

1.2. Conceitos Importantes 5

1.3. Algumas vantagens da Tecnologia de Grupo 7

1.4. Eficiência da Tecnologia de Grupo 8

1.5. Algumas aplicações da Tecnologia de Grupo 9

Capítulo 2. Introdução à Teoria dos Grafos 13

2.1. Introdução 13

2.2. Conceitos 13

2.2.1. Grafos 13

$\begin{array}{ll}\text { 2.2.2. Subgrafo e Grafo Parcial } & 15\end{array}$

2.2.3. Grafo Valorado 16

2.2.4. Grafo Teto 16

2.2.5. Representação Matricial de um Grafo 17

2.2.6. Caminho, Ciclo e Conexidade 17

2.2.7. Ciclo Hamiltoniano c Euleriano 19

$\begin{array}{ll}\text { 2.2.8. Grafo Completo e Bipartido } & 19\end{array}$

2.2.9. Clique, Conjunto Independente de Vértices e "Matching" 20

2.2.10. Árvore e Árvore Geradora 21

2.2.11. Alteração Estrutural de um Grafo 23

2.2.12. Planaridade 26

2.3. Coloração dos Vértices de um Grafo 26

2.4. Aplicações 29

2.4.1. O problema dos exames escolares 29

2.4.2. O problema do pensionato 29

Capítulo 3. Algoritmos para Coloração dos Vértices de um Grafo 31

3.1. Heurísticas Seqüenciais 31

3.1.1. A Heurística Dsatur 32

3.1.2. A Heurística RLF 33

3.1.3. A Heurística de Guénoche 35

3.1.3.1 Matriz de Dissimilaridades e Partição 36 
3.1.3.2 Etapas da Heurística

3.2. Exemplo Ilustrativo 41

3.3. Comentários 21

Capítulo 4. Coloração e Projeto de Células de Manufatura 46

4.1. Dados do problema 46

4.2. Algoritmo 46

4.2.1. Matriz de Carga de Trabalho 47

4.2.2 Computação das dissimilaridades $\quad 47$

4.2.3. Decomposição do Sistema de Manufatura 48

4.2.3.1. Construção e coloração do grafo 48

4.2.3.2. Obtenção das famílias de peças 49

4.2.3.3. Obtenção dos grupos de máquinas $\quad 49$

4.3. Exemplo ilustrativo $\quad 50$

4.4. Aplicações 54

4.5. Discussão e Conclusão 58

Conclusão

60

Referências Bibliográficas 


\section{Introdução}

Fazendo-se uma retrospectiva histórica dos sistemas de manufatura, observa-se que com a revolução industrial, o trabalho do artesão, tipicamente manual, foi substituído pela produção em massa, a fim de atender às necessidades de um amplo mercado.

No início da década de 70 , os sistemas de produção baseados na automação rígida começaram a entrar em declínio, e isto resultou da necessidade de atender o consumidor atual, que vive em um ambiente de economia de mercado, onde a vida dos produtos se torna cada vez mais curta, há maiores alternativas e diversificação de produtos, e fortes pressões por preços e prazos.

O ambiente empresarial sente a mudança, caracterizada por poucos níveis hierárquicos dentro da empresa, roteiros de fabricação pré-determinados, necessidade de tornar-se competitivo; enfim, estar inserido dentro deste novo quadro com uma significativa flexibilidade na produção.

Para acompanhar essas mudanças na manufatura, novas tecnologias surgem no cenário mundial. Uma dessas técnicas é a Tecnologia de Grupo (TG), que atualmente vem colaborando significativamente para obtenção de melhores resultados no sistema de manufatura.

A TG é uma técnica de produção industrial que surgiu por volta de 1945 na antiga União Soviética (Burbidge, 1975) e sua repercussão na Europa e Estados Unidos, deu-se a partir da publicação do livro "Introdução a Tecnologia de Grupo" do professor Burbidge em 1975.

A TG é uma técnica de produção que permite organizar de maneira eficiente os sistemas de manufatura dedicados à fabricação sob encomenda e/ou de lotes pequenos e médios. Os métodos baseados sobre o conceito de TG constituem uma resposta eficiente para o setor industrial destinado à produção de lotes pequenos e médios.

Este conceito repousa sobre o agrupamento de peças similares em famílias com o objetivo de fabricá-las em células ou ilhas que reúnem máquinas especialmente selecionadas para este fim. Isto conduz a uma maior automatização, à uma redução do tempo de preparação das máquinas, à uma padronização das ferramentas empregadas e a uma redução dos ciclos de fabricação (Ribeiro e Meguelati, 2002).

Um sistema de produção é composto de um grande número de etapas que individual ou coletivamente, interferem na produtividade de todo o sistema. A etapa de fabricação tem uma importância particular, pois $5 \%$ do tempo destinado à execução de uma peça é ocupado em operações de máquinas e os $95 \%$ restantes são gastos em movimentações e filas de espera. 
Destes $5 \%$ apenas $30 \%$ são reservados à usinagem propriamente dita, uma vez que a preparação das máquinas e outras tarefas consomem a maior parte do tempo (Doumeingts, 1984; Ribeiro e Meguelati, 2002).

Em um sistema de produção organizada em células de fabricação, a administração tornase mais simples e eficiente, decorrência imediata da decomposição do sistema global de produção em subsistemas de menor dimensão. Há uma redução do tempo gasto em transferências entre os postos de trabalho, do tempo de preparação das máquinas, da quantidade de ferramentas, do tamanho dos lotes e do tempo total de fabricação (Mahmoodi et al., 1990).

Um estudo desenvolvido por Askin e Huang (2001) mostra que trabalhadores treinados tornam-se uma parte integrante para a formação de células e para o sucesso do sistema de produção.

O projeto das células de fabricação exige a resolução de um problema matemático bastante complexo (Kusiak, 1987): Dada a matriz incidência na forma [peças $\times$ máquinas] ou [peças $\times$ tipos de máquinas], onde os tipos de máquinas seriam os tornos, fresadoras, etc., e as máquinas seriam um torno ou uma fresadora específicos dentro do parque de máquinas disponível, trata-se de rearranjar as linhas e as colunas desta matriz, de modo a dar-lhe uma estrutura bloco diagonal.

Os elementos concentrados dentro dos blocos diagonais integram as células de fabricação e os que se situam fora dos blocos diagonais são chamados de movimentos intercélulas e, na prática, são indesejáveis. Por isto, quando do projeto das células de fabricação procura-se minimizar o número de movimentos inter-células.

Numerosas técnicas têm sido utilizadas nos últimos anos (Singh, 1993) para efetuar a bloco diagonalização da matriz de incidência, projetar as células de fabricação e implantar a TG na fábrica. Entre elas podemos citar a programação matemática: Kusiak (1987), Boctor (1991, 1996), Shafer et al. (1992), Liao (1994), Viswanathan (1995), Adil et al. (1997), Won (2000); branch and bound: Qattani (1990), Ramabhatta e Nagi (1998); lógica fuzzy: Xu e Wang (1989), Chu e Hayya (1991); algoritmos genéticos: Venugopal e Narendran (1992a), Zhao e Wu (2000), Brown e Sumichrast (2001), Dimopoulos e Mort (2001); redes neurais: Kusiak e Chung (1991), Lee e Malave (1992), Moon e Chi (1992), Mahdavi, Kaushal e Chandra (2001), metaheurísticas como busca tabu e simulated annealing: Venugopal e Narendran (1992), Boctor (1991), Sofianopoulou (1999); análise de dados: Meguelati (1988), Ribeiro e Pradin (1993), Deutsch et al. (1998); coloração em grafos: Ribeiro e Ribeiro (1993), Ribeiro e Alves (1994), Guénoche (1993), Ferreira (1996), Santos (1996). 
Nesta dissertação, apresentamos o estudo que realizamos acerca da TG e do Projeto de Célula de Manufatura com auxílio de coloração em grafos, com o objetivo de o método proposto calcular as dissimilaridades entre as peças e organizar o sistema de produção em famílias de peças e grupos de máquinas.

No primeiro capítulo são introduzidos os conceitos de TG e Células de Manufatura. Apresentamos também as principais vantagens desta técnica juntamente com sua eficiência em sistemas de produção destinados à fabricação de lotes de pequeno e médio porte, e/ou sob encomenda.

O segundo capítulo é dedicado à apresentação dos principais conceitos e problemas pertinentes à Teoria dos Grafos. Neste estudo interessa-nos fundamentalmente as técnicas de coloração em grafos, tendo em vista a aplicabilidade das mesmas na resolução de problemas de particionamento.

No terceiro capítulo são apresentados algoritmos usados para coloração de vértices de um grafo, como as heurísticas seqüenciais de Brélaz (1979) e Leighton (1979). Neste capítulo é feito um estudo e apresentação do algoritmo de Guénoche (1993) para determinação de uma kcoloração sobre um grafo construído a partir de uma matriz de dissimilaridade entre peças. $\mathrm{O}$ algoritmo é constituído de 3 etapas e faz uso de procedimentos aproximados para determinação de um teto e de uma coloração para o subgrafo obtido. Um exemplo ilustrativo destes algoritmos é estudado e apresentado.

No quarto capítulo é apresentado um estudo detalhado do método e da implementação computacional desenvolvida neste trabalho. Trata-se de um método para o projeto de células de manufatura baseado em coloração em grafos que a exemplo de Ribeiro e Ribeiro (1993) e Ribeiro e Alves (1994). Apresenta bons resultados em termos de qualidade da solução obtida e de tempo de cálculo. $\mathrm{O}$ programa computacional foi escrito em linguagem Delphi e testado utilizando-se um microcomputador Pentium $200 \mathrm{MHz}$ com 64 Mbytes.

Na conclusão é apresentada uma reflexão acerca do trabalho realizado e as perspectivas que julgamos mais interessantes para sua continuidade. 


\section{Capítulo1. Projeto de Células de Manufatura}

Neste capítulo é apresentada uma metodologia de organização e produção industrial denominada Tecnologia de Grupo, destinada principalmente à aplicação em sistemas de manufatura dedicados à produção em lotes pequenos e médios, e/ou sob encomenda.

\subsection{Tecnologia de Grupo}

Em um sistema de manufatura procura-se agilizar a produção, enxugá-la, torná-la mais rápida, sem, contudo, perder a qualidade. Isto decorre do aumento da competitividade e do desenvolvimento de novas tecnologias e aperfeiçoamento das existentes.

Em busca de maior eficiência, por volta de 1945 surgiu uma nova técnica de produção industrial denominada Tecnologia de Grupo (TG). Os conceitos principais da técnica foram apresentados no livro "Princípios Científicos da Tecnologia de Grupo" de S. P. Mitrofanov (1959), publicado na antiga União Soviética. A repercussão desta nova técnica na Europa e nos Estados Unidos deu-se a partir da publicação do livro "Introdução à Tecnologia de Grupo" do professor inglês J. L. Burbidge (1975).

A idéia básica da TG consiste em decompor o sistema global de manufatura em subsistemas mais fáceis de administrar que o sistema em sua totalidade. Esta decomposição é feita procurando-se agrupar as peças que apresentam similaridades geométricas e/ou que se submetem às mesmas operações durante o processo de fabricação, e agrupar as máquinas que executam as operações necessárias sobrc estas peças de modo a obter sub-fábricas o mais independentes possíveis umas das outras.

No desenvolvimento da indústria, constatou-se que em certos setores seria mais vantajoso trabalhar em lotes pequenos e médios, mesmo no caso de indústrias de grande porte. Com esta visão do sistema industrial, a TG conquistou rapidamente seu espaço no campo tecnológico e científico, e muitos pesquisadores passaram a se dedicar ao estudo da técnica.

Uma decomposição de um sistema de manufatura em sub-fábricas completamente independentes está ilustrado na Figura 1.1. Na nova configuração, a família de peças 1 (constituída pelas peças P1 e P3) será processada em uma sub-fábrica independente, composta pelas máquinas 8, 9 e 10; a família de peças 2 (peças P2, P4 e P5) pelas máquinas 6, 5 e 7 e a família de peças 3 (peças P6, P7 e P8) pelas máquinas 1, 2, 3 e 4 . 


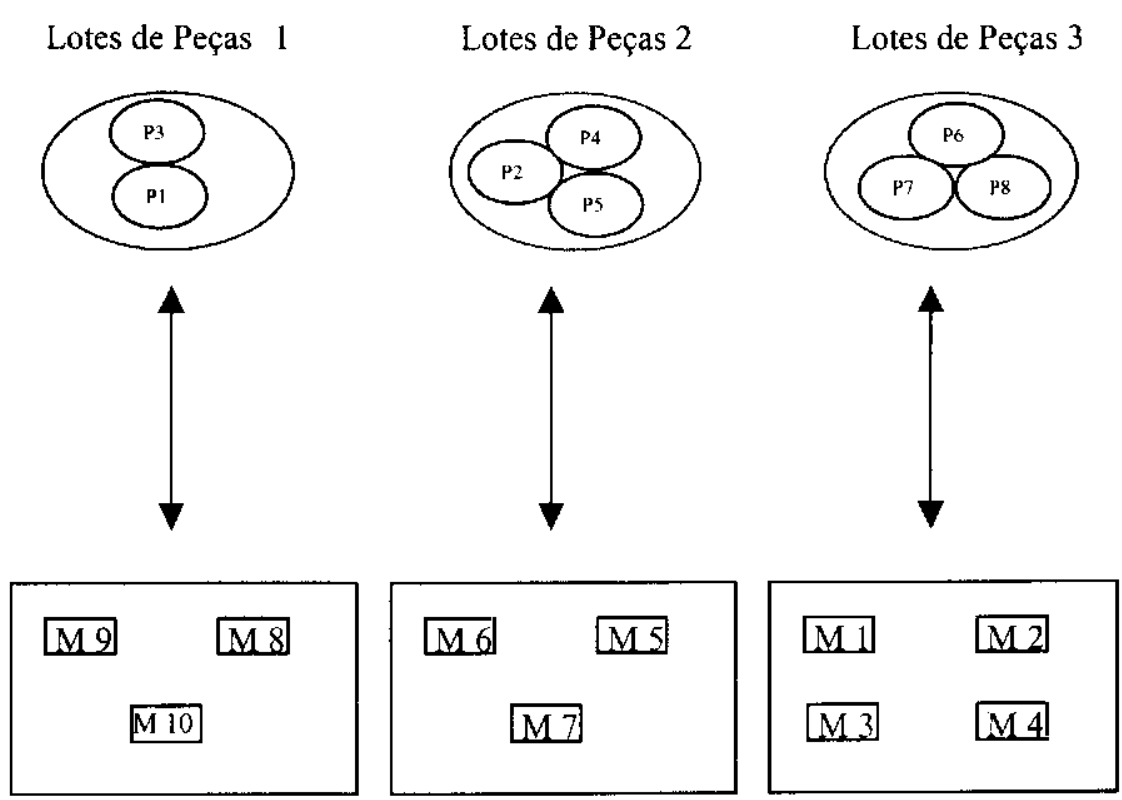

Figura 1.1: Decomposição de uma fábrica em três sub-fábricas independentes.

\subsection{Conceitos Importantes}

Definição 1: Um conjunto de peças que apresentam similaridades de projeto e/ou fabricação é chamado de família.

Definição 2: Um conjunto de máquinas agrupadas para executar todas (ou a maioria) das operações sobre as peças de uma determinada família é chamada de grupo.

A Figura 1.1 mostra o agrupamento de peças em três famílias e das máquinas cm três grupos, a saber:

Família $1=\{P 1, P 3\}$

Família $2=\{\mathrm{P} 2, \mathrm{P} 4, \mathrm{P} 5\}$

Família $3=\{\mathrm{P} 6, \mathrm{P} 7, \mathrm{P} 8\}$

$$
\begin{aligned}
& \text { Grupo } 1=\{\mathrm{M} 8, \mathrm{M} 9, \mathrm{M} 10\} \\
& \text { Grupo } 2=\{\mathrm{M} 5, \mathrm{M} 6, \mathrm{M} 7\} \\
& \text { Grupo } 3=\{\mathrm{M} 1, \mathrm{M} 2, \mathrm{M} 3, \mathrm{M} 4\}
\end{aligned}
$$

Observação: Às vezes não é interessante fazer o agrupamento físico das máquinas, como por exemplo, nos casos de:

- o chão da fábrica não permite o rearranjo das máquinas;

- o custo para rearranjar as máquinas é alto;

- quando há mudanças freqüentes na linha de produtos; 
- se as máquinas estão fixas e não se pode removê-las do lugar.

Quando uma destas situações ocorre, descarta-se então a implementação integral de todas as alterações físicas previstas em um plano de implantação da TG. Pode-se, então, fazer um "uso lógico" das informações contidas em um projeto de famílias e grupos, levando-se em conta peças que utilizam as mesmas máquinas, das máquinas que deveriam estar fisicamente mais próximas, etc. O "uso lógico" seria, então, utilizado com o objetivo de administrar a fábrica com maior eficiência.

Definição 3: O par formado por uma familia e um grupo de máquinas é chamado de célula de manufatura.

Nem sempre é possivel obter células de manufatura totalmente independentes umas das outras. Quando isto ocorre, existe pelo menos uma peça que requer operações em máquinas que não estão em sua célula de atribuição. Este problema pode ser resolvido da seguinte maneira:

- $\quad$ transportando a peça até a máquina requerida;

- duplicando as máquinas que estão sendo requeridas em mais de uma célula;

- $\quad$ parar de fabricar esta peça;

- $\quad$ em vez de produzi-la, pode ser mais viável comprá-la.

Definição 4: A transferência de uma peça de uma célula de manufatura para outra célula é chamada de movimento inter-células.

Definição 5: A peça que necessita do movimento inter-células é chamada de peça problema.

Definição 6: As máquinas que executam operações em peças provenientes de outras células são chamadas de máquinas problema.

Definição 7: A passagem de uma peça por uma máquina é chamada de operação.

Definição 8: A máquina com a maior carga de trabalho na fábrica é chamada de máquina gargalo. 
Devem-se tomar alguns cuidados quando a sobrecarga de trabalho sobre a máquina gargalo é muito alta. $\mathrm{O}$ ideal seria duplicar esta máquina e caso isso não seja possível, deve-se freqüentemente fazer revisões na mesma para evitar quebras que prejudicariam bastante a produção.

\subsection{Algumas vantagens da Tecnologia de Grupo}

A implantação da TG no sistema de manufatura pode fornecer as seguintes vantagens (Ribeiro, 1991):

- as células de manufatura podem aumentar a produtividade da indústria, diminuindo assim o tempo de movimentação, por exemplo, e conseqüentemente o tempo de entrega;

- trabalhando-se com células de manufatura, diminui o tempo perdido no transporte das peças às máquinas e deixa de existir a decisão sobre a máquina efetiva para executar uma dada operação, ou seja, há diminuição do trabalho em processo;

- conhecendo a destinação de cada peça, o transporte é facilitado e conseqüentemente pode-se intensificar o trabalho;

- executando-se as operações sobre as peças nas máquinas mais adequadas, espera-se diminuir o número de horas de retrabalho e os refugos;

- as similaridades entre as peças a serem fabricadas em uma mesma célula de manufatura, permitem uma redução do tempo de regulagem das máquinas ("set-up"), a utilização de um mesmo ferramental, uma diminuição do trajeto das peças pela fábrica, etc;

- pode-se ainda, reduzir a burocracia e melhorar o relacionamento humano entre os funcionários. 


\subsection{Eficiência da Tecnologia de Grupo}

Existem, entretanto, dúvidas quanto à eficiência da decomposição de um sistema de manufatura automatizado. Estudos (Kusiak, 1988) têm mostrado que a partição das máquinas em grupos pode limitar a flexibilidade do sistema. Entretanto, para muitas aplicações industriais, (Hyer e Wemmerlöw, 1989) mostram que é muito dificil operar um sistema de manufatura de grande porte sem a decomposição do mesmo cm células de manufatura. Há pelo menos quatro fatores que sustentam esta tese, como segue:

a) Volume de informações: em um sistema de manufatura automatizado de grande porte o volume de informações geralmente é grande e pode ser muito caro efetivar o processamento das informações sem a decomposição do sistema.

b) Sistema de manuseio e transporte de materiais: em um sistema de manufatura automatizado típico, para carregar o material utilizado pode ser utilizados "automated guided vehicles" (AGV - veículos guiados automaticamente) ou robôs. Cada um destes carregadores pode atender um número limitado de máquinas. Esta limitação é imposta por:

- número máximo de viagens que um AGV pode fazer por unidade de tempo;

- o caminho de orientação do $\mathrm{AGV}$, por exemplo, um trilho, que não poderia ser interceptado por outro caminho de orientação na área de trabalho de AGV.

c) Exigências tecnológicas: algumas máquinas devem ser arranjadas fisicamente próximas devido a exigências tecnológicas, por exemplo: uma máquina de forjar e uma estação de tratamento térmico (aquecedor).

d) Controle ou administração: na maior parte de um sistema automatizado de manufatura, o grau de automatização é maior que nos sistemas clássicos. Dada a dimensão limitada de cada grupo de máquinas, o sistema de manufatura decomposto em células é mais fácil de gerenciar que um sistema organizado por função (seção de tornos, seção de fresadores, etc.). 


\subsection{Algumas aplicações da Tecnologia de Grupo}

- Uma aplicação da Tecnologia de Grupo é apresentada por Oliveira et al. (1999) em uma fábrica da região de Ribeirão Preto, a DMB Implementos Agrícolas. Estes desenvolveram um estudo com o objetivo de analisar a viabilidade da implementação de células de manufatura e propor o agrupamento de máquinas. Os três principais componentes da pesquisa foram:

- Questões em estudo: as questões investigadas na DMB foram: a) Por que a implementação de células de manufatura traria benefícios para a DMB? b) Qual seria o tipo de células de manufatura resultante da nova disposição das máquinas?

- Objetivos: a) O arranjo físico celular proporciona melhores relações humanas, melhora na especialização do operador, oferece menores estoques durante o processo e manuseamento de materiais, reduz os tempos de preparação (set-ups) de produção e reduz os custos de mão-de-obra, sendo estes os benefícios esperados com a sua implantação na DMB. b) As células de manufatura seriam do tipo fábricas dentro da fábrica, conforme Slack et al, (1997), ou seja, possuiriam todos os recursos diretos e indiretos necessários para completar o processo de transformação.

- Unidade estudada: obter o arranjo físico celular da fábrica da DMB, em Sertãozinho, região de Ribeirão Preto.

Este estudo foi feito, pois a DMB reconheceu que sua habilidade para competir no mercado dependia do desenvolvimento de estratégias de produção propriamente alinhadas com sua missão de atender as necessidades dos clientes. Assim a DMB considerou a possibilidade da implementação de células de manufatura em sua fábrica, buscando maior eficiência em sua linha de produção. É uma fábrica onde o número de peças processadas por suas máquinas é muito elevado, da ordem de 3500 peças diferentes, e destas, várias peças tem seu processo de fabricação extremamente artesanal, devido à complexidade de sua geometria.

$\mathrm{Na}$ DMB são produzidos pequenos lotes de um número grande de diferentes produtos, a maioria dos quais requer um conjunto ou seqüência diferente de etapas de processamento. E, assim, utilizou-se a TG para organizar a produção dividindo o processamento dos materiais em unidades organizacionais (células de manufatura). O projeto de células de manufatura na DMB relatado no artigo, apresentou 314 movimentos inter-células, ou seja, não se obteve sub-fábricas independentes uma da outra. Mesmo assim, a gerência da DMB compreendeu que a divisão das máquinas e peças em células facilitaria a sua tarefa de gerenciamento. 
- Uma aplicação da TG em 3 indústrias paulistas é apresentada por Ferreira e Resende (1995). Foi desenvolvido um estudo procurando relacionar os sistemas de PCP (Planejamento e Controle de Produção) e suas aplicações em células de fabricação por indústrias brasileiras. Para tanto, fez-se inicialmente um estudo pormenorizado do conceito de células de manufatura, procedimentos de PCP e critérios para seleção de sistemas de PCP em geral e, em particular, para sistemas de fabricação em células à luz da Tecnologia de Grupo. A seguir, procedeu-se a pesquisa de campo através de entrevistas e observações do sistema em funcionamento junto ao processo produtivo, guiados por um questionário elaborado com os principais tópicos: 1) Empresa: linha de produtos, número de empregados e faturamento; 2) Sistema produtivo e sua operação: tipos e proporção dos arranjos físicos da fabricação, número de células, máquinas por células, etc.; 3) Estratégia de fabricação: para estoque, por ordem, encomenda de projetos; 4) Planejamento e controle de produção: atribuições, plano mestre de produção, planejamento de capacidade, programação; 5) Dificuldades enfrentadas para implementação de células: reação da administração, reação dos empregados; 6) Melhorias desejáveis.

Foram escolhidas fábricas de sistemas de produção bastante diferenciados e que tivessem participação significativa no mercado em termos quantitativos e qualitativos.

A empresa A, fabricante de freios automotivos, estava dividida em duas unidades independentes: uma para veículos leves e outra para veículos pesados.

A empresa B, grande fabricante de elevadores de edifícios e escadas rolantes, operava uma grande fábrica, constituída de 105 unidades, distribuídas em 7 mini-fábricas de 15 células cada.

A empresa $\mathrm{C}$ é grande fabricante de equipamentos para geração de energia elétrica e extração de petróleo. Possui 4 células, sendo que duas não eram operadas pela Tecnologia de Grupo.

Os dados levantados deram base para algumas conclusões, como:

As empresas pesquisadas são de grande porte e procuravam se organizar para enfrentarem a concorrência a nível mundial e, portanto, não servem para conclusões extensivas às indústrias brasileiras em geral, mas como referência.

As empresas A e B quase que completamente organizadas em células, romperam a estrutura tradicional de PCP usual, adotando um sistema de controle de produção de "puxar", mas mantiveram um MRP tradicional, sem adaptações. Conseqüentemente, não há uma integração do planejamento (MRP) com o controle de produção (Kanban). A empresa C, com 
apenas duas células, manteve a estrutura de PCP tradicional. Em todos os casos, o MRP desconhece a composição de famílias entre os ítens, e as ordens que planeja servem (nos casos de A e B) apenas como previsão para os Kanbans.

O planejamento de capacidade teve modificações para se ajustar ao conceito de células. $\mathrm{Na}$ área de seqüenciamento/programação, nenhuma empresa pesquisada aparentemente desenvolveu algum procedimento formal para seqüenciamento de família de ítens. Os supervisores de produção ou programadores seqüenciavam os trabalhos com o objetivo de evitar set-ups elevados. A empresa $\mathrm{C}$ teve maiores preocupações nessa área, chegando a desenvolver um algoritmo próprio para seqüenciamento de ordens. Não houve, segundo as empresas pesquisadas, maiores dificuldades na formação de células.

Estas empresas aprenderam fazendo, conseguindo atingir um estágio importante para chegar ao grau superior de organização de sistemas de manufatura. Com a organização da fábrica em células de manufatura, o envolvimento de todos os empregados, a melhoria de qualidade, a redução de estoques, a possibilidade de respostas mais rápidas às solicitações do mercado, a sobrevivência e o crescimento das indústrias, podem ser perfeitamente possíveis. A integração da Tecnologia de Grupo com o MRP e este com Kanban, reforça as bases de JIT (just-in-time), e para estes autores, esta é a filosofia de manufatura que deve ser adotada com urgência pelas empresas brasileiras que ainda não fizeram.

- Os resultados obtidos em 33 empresas paulistas usuárias da Tecnologia de Grupo estão descritos por Arruda e Vila $F^{o}$ (1994). Estes resultados foram obtidos a partir de um questionário estabelecido em função de uma pesquisa bibliográfica e utilizado para levantar o estágio atual da implantação da Tecnologia de Grupo e Células de Manufatura no Estado de São Paulo. Este questionário foi enviado para 73 empresas potenciais usuárias da TG e CM, sendo a maioria de grande porte. Destas, apenas 35 empresas responderam e destas verificouse que $33(94,29 \%)$ eram usuárias ou pretendiam utilizar a TG em um futuro próximo e 31 $(88,57 \%)$ eram usuárias ou pretendiam usar CM.

Analisados os resultados do levantamento, muitas lições foram aprendidas pelos atuais e futuros usuários de novas técnicas. Entre elas:

- Os fatores, a seguir descritos, devem ser analisados antes ou até paralelamente à implantação da TG e CM: treinamento e seleção de pessoal; iniciar pelos projetos com alta probabilidade de sucesso; ir lentamente; não estimar muito baixo o tempo de implementação (em média, entre 1 e 3 anos) e manter o pessoal envolvido bem informado. 
- Na fase de planejamento da CM, é essencial uma análise da TG; da vida e do ciclo do produto; a mistura do fluxo; os conceitos de padronização; o custo e a alocação do ferramental e a precisão e planejamento de operações, para o reprojeto posterior das células.

- A experiência das pessoas envolvidas é primordial para o sucesso da CM. O recrutamento de pessoal antes envolvido com este tipo de trabalho permite um melhor desenvolvimento do projeto. O treinamento é o fator principal para o sucesso do projeto.

- É bastante específico o processo de implementação de células, mas alguns fatores não podem ser esquecidos, tais como: iniciar pela célula piloto (recurso que auxilia o empresário a analisar os resultados de uma célula experimental); selecionar a primeira célula simples e com alto potencial de sucesso; não depender da célula exclusivamente como fonte de suprimentos durante a implementação; orientação plena sobre as razões da mudança e objetivos do programa. 


\section{Capítulo 2. Introdução à Teoria dos Grafos}

\subsection{Introdução}

Neste capítulo são apresentados conceitos fundamentais, bem como alguns problemas típicos da Teoria dos Grafos. Para um estudo mais completo, consultar: Berge (1970), Sakarovitch (1984), Gondran e Minoux (1985), etc. Em particular, interessa-nos o estudo de coloração em grafos, uma vez que podem auxiliar no desenvolvimento de métodos para realização do projeto de células de manufatura.

\subsection{Conceitos}

Os conceitos são estudados nos itens abaixo e diversos exemplos são utilizados para ilustrar estes conceitos.

\subsubsection{Grafos}

Definição 1: Um grafo $G(V, A)$ é um conjunto finito não vazio $V$ constituido de elementos denominados vértices ou nós e um conjunto $\mathrm{A}$ que pode ser de pares não-ordenados ou ordenados de elementos de $\mathrm{V}$, denominados arestas ou arcos de $\mathrm{G}$, respectivamente.

Definição 2: Se A é constituido de pares ordenados, diz-se que G é um grafo orientado, caso contrário G será não-orientado.

O termo grafo será utilizado tanto para grafos orientados quanto para grafos nãoorientados. Boa parte das nomenclaturas e dos conceitos são análogos tanto em um caso como no outro.

Cada aresta $\mathrm{a} \in \mathrm{A}$ será denotada pelo par de vértices $\mathrm{a}=(\mathrm{i}, \mathrm{j})$ que a define. Neste caso, os vértices i e j são os extremos da aresta a e denominados adjacentes. A aresta a é dita incidente a ambos i e j. Duas arestas que possuem um extremo em comum são chamadas de adjacentes.

A notação $|\mathrm{V}| \mathrm{e}|\mathrm{A}|$ indica o número de elementos de $\mathrm{V}$ e $\mathrm{A}$, respectivamente.

Um grafo pode ser visualizado através de uma representação geométrica, na qual seus vértices correspondem a pontos distintos do plano em posições arbitrárias, e a cada aresta $\mathrm{a}=(\mathrm{i}, \mathrm{j})$ 
é associada uma linha arbitrária unindo os pontos correspondentes i e j. A Figura 2.1, ilustra o exemplo de um grafo $\mathrm{G}(\mathrm{V}, \mathrm{A})$ com 6 vértices e 11 arestas.

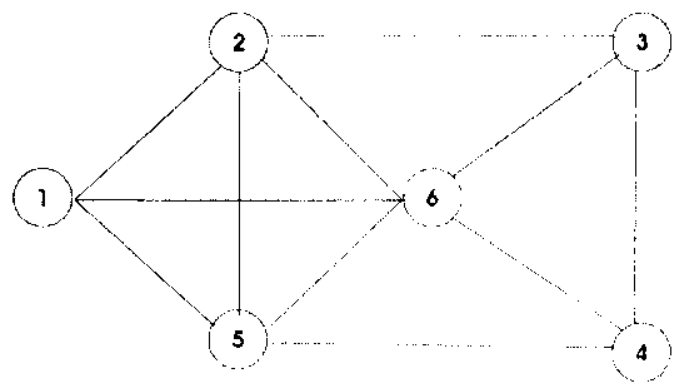

Figura 2.1

$\mathrm{V}=\{1,2,3,4,5,6\},|\mathrm{V}|=6$

$A=\{(1,2),(1,5),(1,6),(2,3),(2,5),(2,6),(3,4),(3,6),(4,5),(4,6),(5,6)\},|A|=11$

Em um grafo orientado, um arco do tipo a $=(i, j)$ é admissível e chamado de laço. A Figura 2.2 mostra o arco $a=(4,4)$ é um laço.

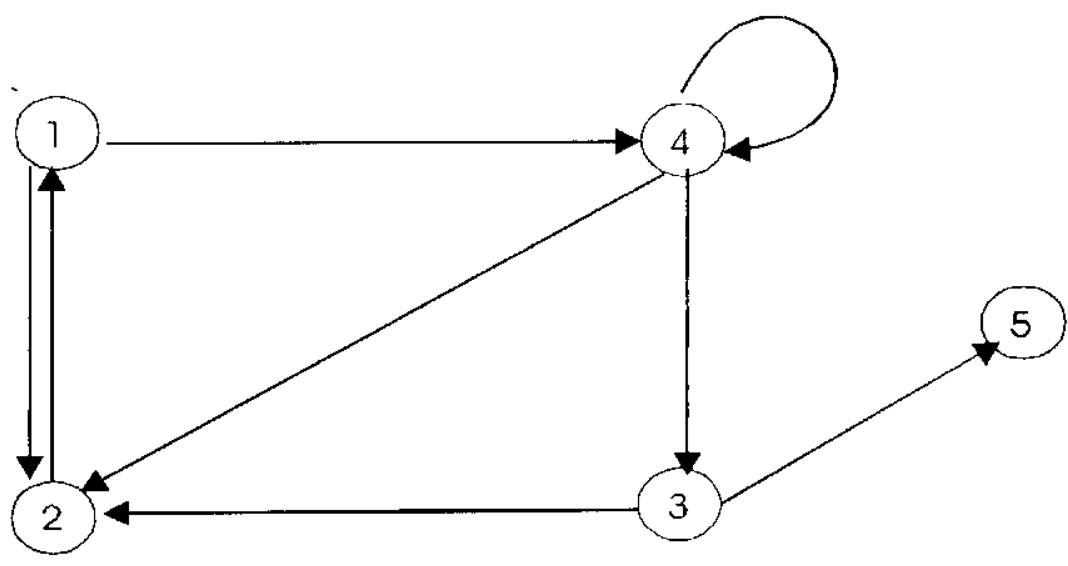

Figura 2.2

Na definição de grafo, pode-se substituir, o conjunto de arestas A, por um multiconjunto. Com isto, é possível ter mais de uma aresta entre o mesmo par de vértices. Estas arestas são denominadas de arestas paralelas.

Definição 3: Um grafo contendo arestas paralelas é dito um multigrafo. 
A Figura 2.3 mostra um multigrafo com 3 arestas entre os vértices 3 e 4.

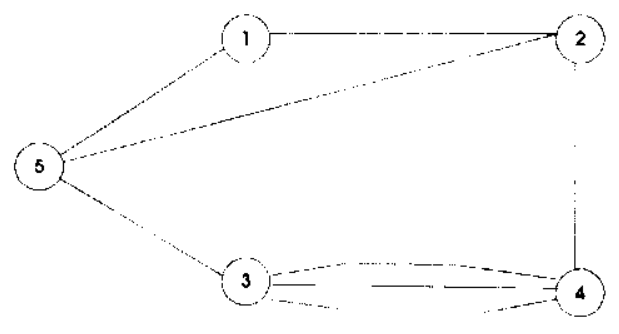

Figura 2.3

Definição 4: Em grafo $G(V, A)$, define-se grau de um vértice $i \in V$, como sendo o número de arestas incidentes a $\mathrm{i}$.

Na Figura 2.3, o vértice 2 tem grau 3 c o vértice 3 tem grau 4 .

\subsubsection{Subgrafo e Grafo Parcial}

Definição 5: Sejam $G(V, A)$ e $G_{1}\left(V_{1}, A_{1}\right)$ dois grafos. Se $V_{1} \subseteq V$ e $A_{1} \subseteq A$ dizemos que $G_{1}\left(V_{1}, A_{1}\right)$ é um subgrafo de $G(V, A)$.

Um nome especial é dado aos subgrafos $G_{1}\left(V_{1}, A_{1}\right)$ de um grafo $G(V, A)$, a saber, subgrafos induzidos, se $G_{1}\left(V_{1}, A_{1}\right)$ satisfazer a seguinte propriedade: toda aresta $(i, j)$ de $G(V, A)$ é aresta de $G_{1}\left(V_{1}, A_{1}\right)$ onde $i, j \in V_{1}$, ou seja, se $i, j \in V_{1}$ e a aresta $(i, j) \in A$ então $(i, j) \in A_{l}$, veja a Figura 2.4 .

Definição 6: Um grafo parcial $G_{1}\left(V_{1}, A_{1}\right)$ de um grafo $G(V, A)$ é um grafo tal que $A_{1} \subseteq A$.

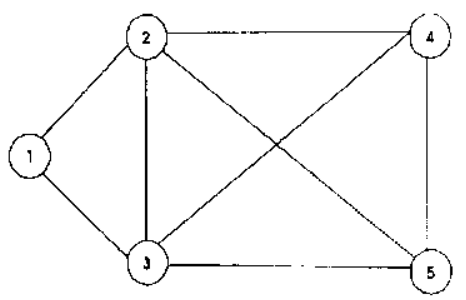

(a)

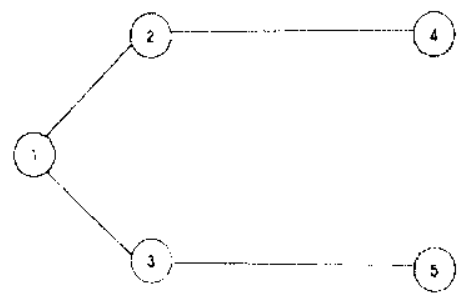

(b)

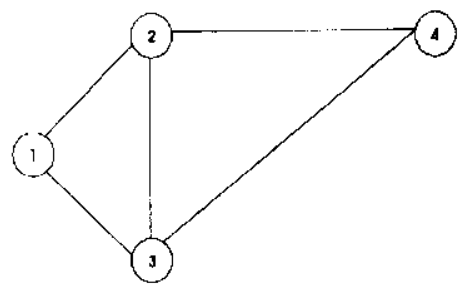

(C)

Figura 2.4

Os grafos da Figura 2.4(b) e 2.4(c) são ambos subgrafos da Figura 2.4(a). Mas somente o da figura 2.4(c) é induzido. 


\subsubsection{Grafo Valorado}

Definição 7: Diz-se que um grafo $G(V, A)$ é valorado quando a cada aresta de $A$ ou vértice de $\mathrm{V}$, está associado um peso $\omega$ (a). O significado deste peso depende de cada problema especifico, podendo corresponder a distância, fluxos, etc.

Definição 8: Em um grafo valorado, o comprimento de uma aresta a $=(i, j)$ em um grafo valorado é a imagem de uma função peso $\omega$ associado à aresta a.

Na Figura 2.5, a aresta $a=(2,4)$ tem peso $\omega(\mathrm{a})=12$

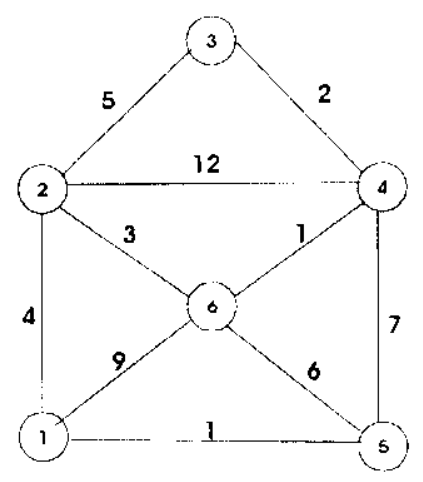

Figura 2.5

\subsubsection{Grafo Teto}

Definição 9: Dado um indice $s \geq 0$, define-se como grafo teto. $G_{s}\left(V, A_{s}\right)$, o subgrafo parcial de $G(V, A)$ tal que $\left(x_{i}, x_{j}\right) \in A_{s} \Leftrightarrow \omega\left(x_{i}, x_{j}\right) \geq s$.

A Figura 2.6 ilustra o grafo teto $G_{6}$, subgrafo parcial do grafo da Figura 1.6.

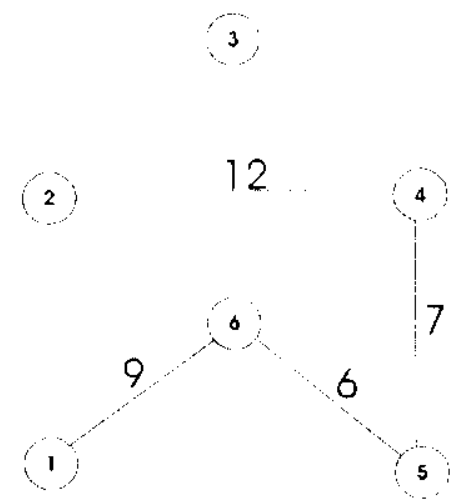

Figura 2.6 


\subsubsection{Representação Matricial de um Grafo}

Pode-se associar a um grafo não-orientado uma matriz de valores ou pesos $P=\left[a_{i j}\right]$ definida por:

$$
a_{i j}=\left\{\begin{array}{c}
\omega(\mathrm{i}, \mathrm{j}) \Leftrightarrow \exists(\mathrm{i}, \mathrm{j}) \\
0 \text { caso contrário }
\end{array}\right.
$$

Obs.: A matriz de valores de um grafo não-orientado é sempre simétrica pois se $a_{\mathrm{ij}} \neq 0, \mathrm{a}_{\mathrm{ij}}=\varpi(\mathrm{i}, \mathrm{j})$ $=\omega(\mathrm{j}, \mathrm{i})=\mathrm{a}_{\mathrm{ij}}$.

A Figura 2.7 fornece a matriz $\mathrm{P}$ associada ao grafo da Figura 2.6.

$$
P=\left[\begin{array}{cccccc}
0 & & & & & \\
0 & 0 & & & & \\
0 & 0 & 0 & & & \\
0 & 12 & 0 & 0 & & \\
0 & 0 & 0 & 7 & 0 & \\
9 & 0 & 0 & 0 & 6 & 0
\end{array}\right]
$$

Figura 2.7

Existem outras representações de um grafo $G$ por meio de matriz (Netto, 1979).

\subsubsection{Caminho, Ciclo e Conexidade}

Definição 10: Uma seqüência de vértices $v_{1}, v_{2}, \ldots, v_{k}$ tal que $\left(v_{j}, v_{j+1}\right) \in A, 1 \leq j \leq k-1$, é denominado caminho de $v_{1}$ a $v_{k}$. Se todos os vértices do caminho $v_{1}, v_{2}, \ldots, v_{k}$ forem distintos, a seqüência recebe o nome de caminho simples ou elementar.

Definição 11: O comprimento de um caminho é o número de arestas que o compõe (se o grafo for valorado, o comprimento do caminho é dado pela soma dos pesos das arestas que o compõe).

Definição 12: A distância d(i,j) entre dois vértices $i, j$ de um grafo é o comprimento do menor caminho entre i e j. 
Definição 13: Uma cadeia é uma seqüência de arestas, onde as arestas são ligadas umas as outras por uma extremidade qualquer. Define-se de modo análogo, cadeia elementar e cadeia simples.

Definição 14: Um ciclo é um caminho $v_{1}, v_{2}, \ldots, v_{k}, v_{k+1}$ sendo $v_{t}=v_{k+1}, k \geq 3$. Define-se da mesma maneira que para um caminho, um ciclo elementar.

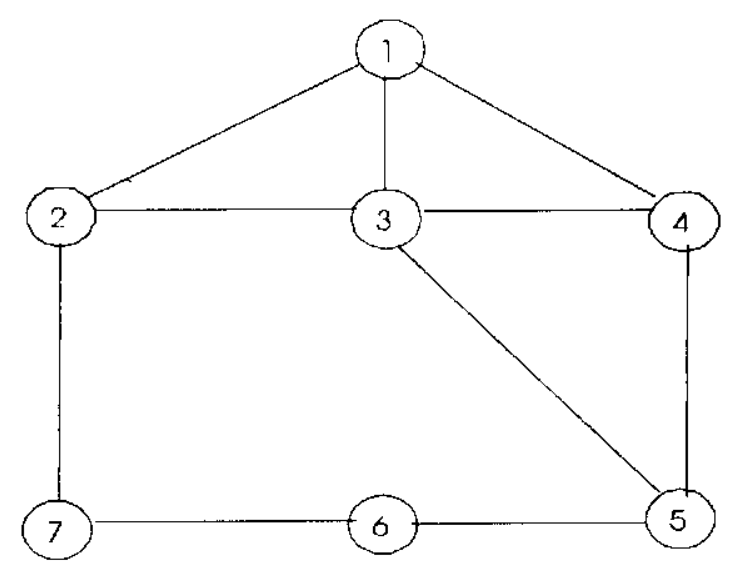

Figura 2.8

Na Figura 2.8 o caminho 1, 2,3, 4 é simples ; 1, 2, 3, 4, 1 é um ciclo simples; d(1,5)=2.

Definição 15: Um grafo $G(V, A)$ é dito conexo quando existe um caminho entre cada par de seus vértices. Caso contrário, $\mathrm{G}$ é desconexo.

O grafo da Figura 2.8 é conexo enquanto o grafo da Figura 2.6 é desconexo.

Obs.: Seja S um conjunto e $\mathrm{S}^{\prime} \subseteq \mathrm{S}$. Diz-se que S'é maximal em relação a uma certa propriedade $\mathrm{P}$ quando S'satisfaz P e não existe $S$ ' $\supset S$ ' $(S$ ' $\subseteq S)$ tal que S' satisfaça $P$. De modo análogo, definese conjunto minimal. Observe que $S$ 'não precisa ser o maior subconjunto de $S$ que satisfaça $P$.

Definição 16: Os componentes conexos de um grafo são os subgrafos maximais de $\mathrm{G}$ conexos. 


\subsubsection{Ciclo Hamiltoniano e Euleriano}

Definição 17: Um caminho ou ciclo é Euleriano quando contém cada aresta do grafo somente uma vez.

Definição 18: Um caminho é Hamiltoniano se for elementar e contenha todo vértice do grafo. Da mesma forma define-se ciclo Hamiltoniano.

Se $G(V, A)$ é um grafo que possui um ciclo Hamiltoniano ou Euleriano, então G é denominado Hamiltoniano ou Euleriano, respectivamente.

Os seguintes teoremas são importantes para a identificação de grafos Hamiltonianos ou Eulerianos, respectivamente:

Teorema: Seja $G(V, A)$ um grafo com pelo menos 3 vértices tal que grau(i) $\geq|S| / 2$ para todo vértice $i \in V$. Então G é Hamiltoniano.

Teorema de Euler: Um grafo é Euleriano se e somente se ele for conexo e todos os seus vértices tiverem grau par.

O teorema de Euler fornece a condição necessária e suficiente para a existência de um ciclo euleriano em um grafo. O grafo da Figura 2.8 não é Euleriano, pois, os vértices 1, 3, 4 e 5 têm grau ímpar. Até hoje não se conhece uma condição necessária e suficiente para a existência de um ciclo hamiltoniano.

\subsubsection{Grafo Completo e Bipartido}

Definição 19: Um grafo é completo quando existe uma aresta entre cada par de seus vértices. Utiliza-se a notação $K_{n}$ para designar um grafo completo com $n$ vértices.

Definição 20: Um grafo $G(V, A)$ é bipartido quando o seu conjunto de vértices $V$ puder ser particionado em dois subconjuntos $V_{1}, V_{2}$ tais que toda aresta de $G$ une um vértice de $V_{1}$ a outro de $V_{2}$. Denota-se o grafo bipartido $G$ por $G\left(V_{1} \cup V_{2}\right.$, A). Um grafo bipartido completo possui 
uma aresta para cada par de vértices $v_{1}$, $v_{2}$ sendo $v_{1} \in V_{1}$ e $v_{2} \in V_{2}$. Se $n_{1}=\left|V_{1}\right|$ e $n_{2}=\left|V_{2}\right|$, denotamos $\mathrm{G}$ por $\mathrm{Kn}_{1}, \mathrm{n}_{2}$.

O seguinte teorema nos dá um resultado importante para identificação de grafos bipartidos:

Teorema: Um grafo é bipartido se e somente se todo ciclo de G possuir número par de vértices.

Na Figura 2.9, $G(V, A)$ é bipartido completo $K_{3,2}$, sendo $V=V_{1} \cup V_{2}$, com $V_{1}=\{1,2,3\}$ e $\mathrm{V}_{2}=\{4,5\}$.

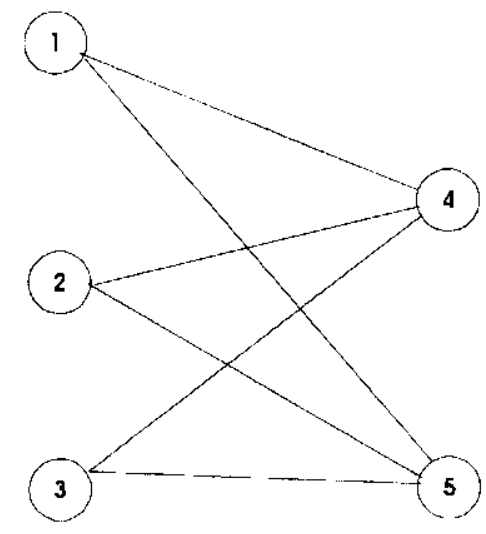

Figura 2.9

\subsubsection{Clique, Conjunto Independente de Vértices e "Matching"}

Definição 21: Seja $G(V, A)$ um grafo. Dizemos que um subgrafo de $G(V, A)$ é uma clique se este for completo.

A Figura 2.10 (b) mostra uma clique $\{1,3,4,5\}$ do grafo da Figura 2.10(a).

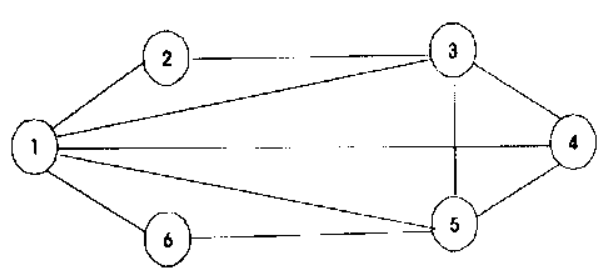

(a)

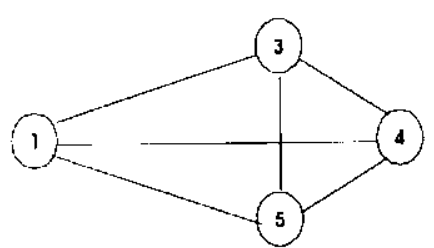

(b)

Figura 2.10 
Definição 22: Seja G(V,A) um grafo. Diz-se que um subgrafo induzido de $G(V, A)$ é um conjunto independente de vértices (SCIE) ou "stable", se este for totalmente desconexo, isto é, não há arestas entre qualquer par de vértices.

Na Figura 2.10(a) o conjunto $\{2,4,6\}$ é independente de vértices.

O tamanho de uma clique ou de um conjunto independente de vértices é igual ao número de elementos de seu conjunto de vértices.

Definição 23: Um "matching" de um grafo G é um subconjunto de arestas de G tal que duas arestas quaisquer pertencentes a este subconjunto não sejam adjacentes.

Na Figura 2.10(a), \{(1,2),(5,6),(3,4)\} é um 'matching"de G.

Definição 24: O número de vértices de um SCIE de maior cardinalidade de um grafo $G$ é chamado número de estabilidade interna, $\alpha(\mathrm{G})$. No pior caso, o problema de determinação dos SCIE maximais é de complexidade exponencial (Netto, 1979).

Definição 25: O complemento de um grafo $\mathrm{G}(\mathrm{V}, \mathrm{A})$ é o grafo $\bar{G}\left(\mathrm{~V}, \mathrm{~A}^{\prime}\right)$ tal que $(\mathrm{i}, \mathrm{j}) \in \mathrm{A} \Leftrightarrow$ (i,j) $\notin A^{\prime}$.

Como a cada SCIE de um grafo G corresponde uma clique do grafo complementar $\bar{G}$, o problema determinação dos SCIE maximais pode ser apresentado como o da determinação de cliques maximais no grafo $\bar{G}$.

\subsubsection{0. Árvore e Árvore Geradora}

Definição 26: Uma árvore $\operatorname{Ar}(\mathrm{V}, \mathrm{A})$ é um grafo conexo e sem ciclos. Um conjunto de árvores é uma floresta.

Definição 27: Se i é um vértice de Ar tal que grau(i)=1, então ele é denominado folha. 
A Figura 2.11 ilustra uma árvore com folhas 4,5,6,7.

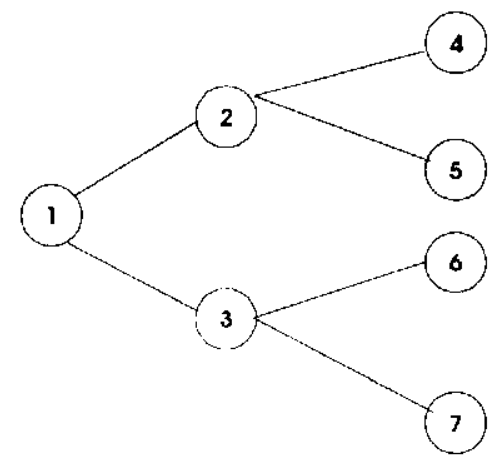

Figura 2.11

Alguns teoremas apresentados abaixo podem ser úteis para caracterização de árvores:

Teorema: Toda árvore com $n$ vértices possui $n-1$ arestas.

Teorema: Um grafo $\mathrm{G}(\mathrm{V}, \mathrm{A})$ é uma árvore se e somente se existir um único caminho entre cada par de vértices de $\mathrm{G}(\mathrm{V}, \mathrm{A})$.

Teorema: Seja G(V,A) um grafo. As seguintes afirmações são equivalentes:

i) G é uma árvore

ii) $\mathrm{G}$ é conexo e $|\mathrm{A}|$ é mínimo

iii) $\mathrm{G}$ não possui ciclos e $|\mathrm{A}|=|\mathrm{V}|-1$

iv) $\mathrm{G}$ é conexo e $|\mathrm{A}|=|\mathrm{V}|-1$

v) $G$ não possui ciclos e para $\forall i, j \in V$, a adição da aresta $(i, j) \notin A$ produ $z$ um grafo contendo exatamente um ciclo.

Definição 28: Um subgrafo gerador de um grafo G(V,A) é um subgrafo parcial de G. Se este subgrafo for um árvore, ele recebe o nome de árvore geradora.

Teorema: Todo grafo conexo G(V,A) possui uma árvore geradora. 
Definição 29: Uma árvore é chamada de árvore de peso máximo (mínimo) quando for um subgrafo gerador de um grafo $\mathrm{G}(\mathrm{V}, \mathrm{A})$ e a soma dos pesos pertencentes às suas arestas for máxima (mínima).

As aplicações de se determinar a árvore geradora mínima (ou máxima) são numerosas (Ferreira, 1996): otimização em redes, classificação hierárquica, etc.

O problema da determinação de uma árvore geradora de peso mínimo pode ser enunciado da seguinte forma (Gondran e Minoux, 1990):

- Considere um grafo G(V, A) valorado. Para cada aresta $a \in A$ associa-se o peso da aresta, $\omega($ a). Seja G'(V, A') um grafo parcial de G. O peso de G'é um parâmetro calculado como se segue:

$$
\omega\left(G^{\prime}\right)=\sum_{a \in G^{\prime}} \omega(a)
$$

- Supõe-se G conexo (se não for, resolve-se separadamente para cada componente conexa). Procura-se, então, uma árvore $\mathrm{Ar}^{*}$ de $\mathrm{G}$ tal que:

$$
\omega\left(A r^{*}\right)=\min \{\omega(A r), \forall A r \subset G\}
$$

\subsubsection{Alteração Estrutural de um Grafo}

Seja G(V, A) um grafo, a $\in$ A uma aresta. Denota-se por G-a o grafo obtido de G, pela exclusão da aresta a. Se $i, j$ é um par de vértices não-adjacentes em $G$, a notação $G+(i, j)$ representa o grafo obtido adicionando a aresta $(i, j)$. Analogamente, seja $i \in V$ um vértice de $G$. $O$ grafo $\mathrm{G}$ - $\mathrm{i}$ denota aquele obtido de $\mathrm{G}$ pela remoção do vértice i. Excluir um vértice implica em remover de $G$ o vértice em questão e as arestas a ele incidentes. Da mesma forma, $G+j$ representa o grafo obtido adicionando-se a $G$ o vértice $j$.

De um modo geral, se $\mathrm{G}$ é um grafo e $\mathrm{X}$ um conjunto de arestas ou vértices, $\mathrm{G}-\mathrm{X}$ e $\mathrm{G}$ + $\mathrm{X}$ denotam, respectivamente, o grafo obtido de $\mathrm{G}$ pela exclusão e inclusão de $\mathrm{X}$, veja a Figura 2.12 . 


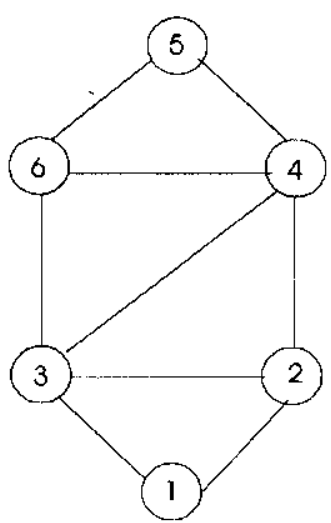

G

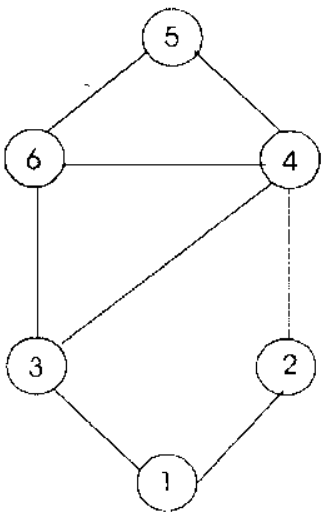

$G-(2,3)$

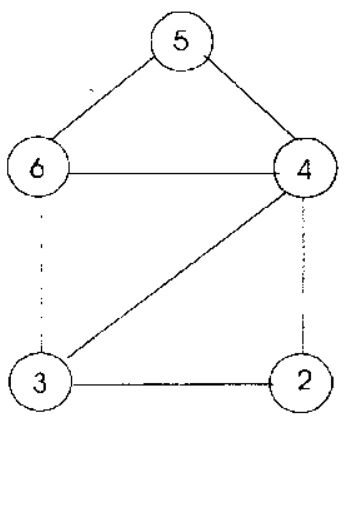

$G-1$

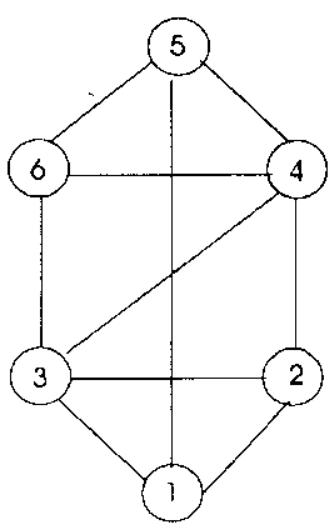

$G+(1,5)$

Figura 2.12

Definição 30: Um vértice v é denominado articulação quando sua remoção de G o desconecta, isto é, $\mathrm{G}-\mathrm{v}$ torna-se desconexo.

Definição 31: Uma aresta a $\in$ A é chamada ponte quando sua remoção de $G$ o desconecta. Neste caso, $\mathrm{G}$ - a também torna-se desconexo.

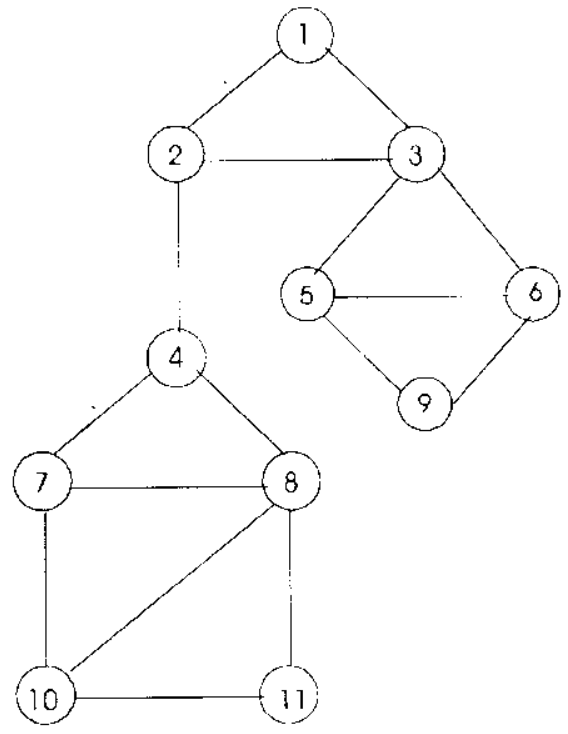

Figura 2.13

Na Figura 2.13 os vértices 2 e 3 são uma articulação, e aresta $(2,4)$ é uma ponte.

Definição 32: Um grafo $G(V, A)$ é chamado de trivial quando $|V|=1$.

Definição 33: Seja $V^{\prime} \subseteq V$, cuja remoção de $G$ o desconccta ou o transforma no grafo trivial e para todo subconjunto próprio $V^{\prime \prime} \subset V^{\prime}, G-V^{\prime}$ é conexo e não trivial. Diz-se que V'é um corte 
de vértices de $G$. Analogamente, um corte de arestas de $G$ é um subconjunto $A^{\prime} \subseteq A$, cuja remoção de $G$ o desconecta, e para todo subconjunto próprio $A$ " $\subset A$ ', $G$ - A" é conexo.

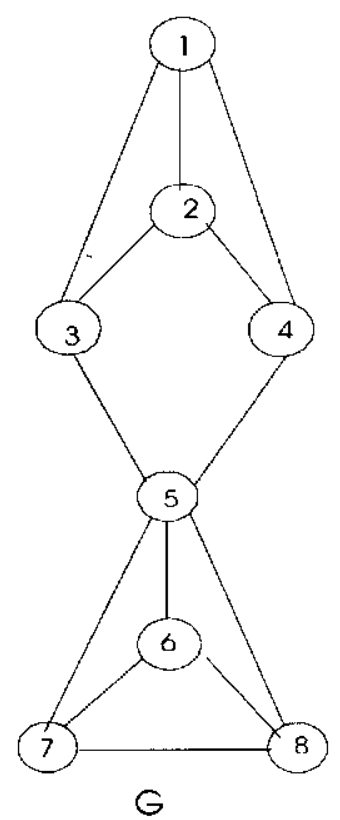

$G$

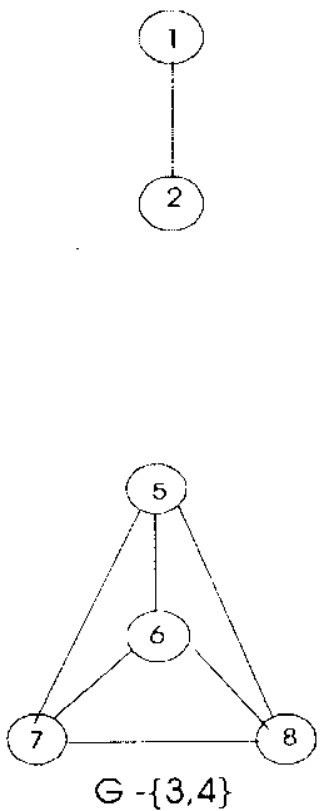

(a)

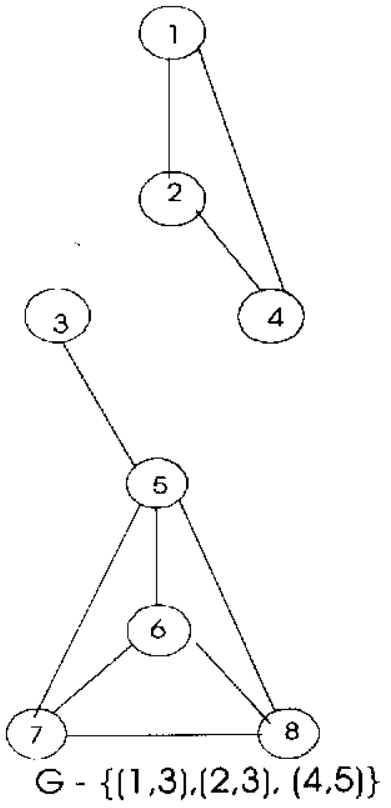

(b)

Figura 2.14

Na Figura 2.14 o subconjunto $\{3,4\}$ é um corte de vértices, pois sua remoção desconecta o grafo G. A Figura 2.14(a) ilustra o caso. Em relação a este mesmo grafo, o subconjunto de arestas $\{(1,3),(2,3),(4,5)\}$ é um corte de arestas, porque removendo-o de $\mathrm{G}$ produz-se o grafo desconexo figura 2.14(b). Observe também que removendo de $\mathrm{G}$ o subconjunto de vértices $\{3$, $4,7\}, \mathrm{G}$ é desconectado. Contudo, $\{3,4,7\}$ não é um corte de vértices, pois contém propriamente o corte $\{3,4\}$.

A determinação do número cromático de um grafo $G$ pode ser feita através de um esquema iterativo de alterações estruturais que visa a determinação de cliques. O objetivo final é a obtenção da clique de cardinalidade mínima.

Algoritmos que se utilizam de operaçõcs de exclusão de vértices ou adição de arestas são do tipo alteração estrutural. Podem ser exatos ou heurísticos. 


\subsubsection{Planaridade}

Seja $G(V, A)$ um grafo e $R$ uma representação geométrica de $G$ em um plano.

Definição 34: A representação $R$ é plana quando não houver cruzamento de arestas em $R$, a não ser nos vértices.

Definição 35: Um grafo é planar quando admite alguma representação plana.

Uma caracterização de planaridade é dada pelo teorema abaixo:

Teorema (Kuratowski): Um grafo é planar se e somente se ele não contém como sugrafo parcial um grafo $K_{3,3}$ ou $K_{5}$.

A Figura 2.15(a), fornece uma representação não plana do grafo completo $\mathrm{K}_{4}$. A Figura 2.15(b) mostra uma representação plana desse grafo; portanto $\mathrm{K}_{4}$ é planar.

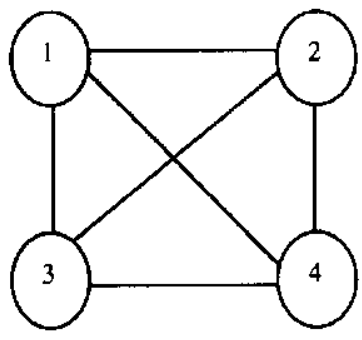

(a)

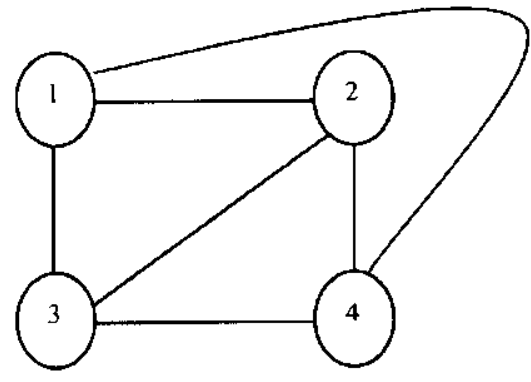

(b)

\section{Figura 2.15}

\subsection{Coloração dos Vértices de um Grafo}

O estudo da coloração em grafos teve início com o chamado "problema das quatros cores". Em 1852, Francis Guthrie formulou uma conjectura de que qualquer mapa poderia ser colorido com quatros cores de modo que países fronteiriços não tivessem a mesma cor.

Se $\mathrm{M}$ é uma região do plano, um mapa é um particionamento de $\mathrm{M}$ em um número finito de regiões, as quais são delimitadas por linhas. Duas regiões são adjacentes quando possuírem uma linha em comum. Uma coloração de $\mathrm{M}$ é uma atribuição de alguma cor a cada região de $\mathrm{M}$, de modo que regiões adjacentes possuam cores diferentes. Pode-se definir um grafo $G$ associando-se um vértice para cada região de $M$ e uma aresta a um par de vértices adjacentes quando as respectivas regiões o forem (Figura 2.16). Então, colorir o mapa $M$ é equivalente a 
colorir G. Logicamente G tem de ser planar. O "problema das quatro cores" consiste, pois, em provar que todo grafo planar é 4-colorível.
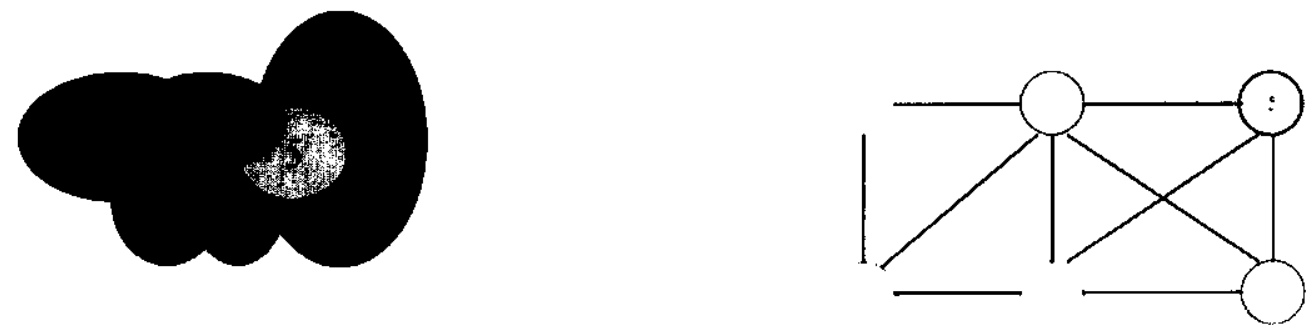

Figura 2.16

Ao longo destes 125 anos, ninguém foi capaz de exibir um mapa em que cinco cores fossem necessárias e muito menos exibir uma prova direta não enumerativa que quatros cores são suficientes. Esta demonstração foi realizada por Appel e Haken (1976) através de uma técnica por computador. Eles utilizaram resultados da teoria dos grafos, entre os quais pode-se citar o trabalho de Heawood (1890), para provar que o númcro geral pode ser reduzido a um número finito de casos particulares, tais que todo grafo planar pode ser colorido com quatro cores. O resultado ficou conhecido como "teorema das quatro cores".

Seja $G(V, A)$ um grafo e $C=\left\{c_{i}, i \in N\right\}$ um conjunto de cores. Uma coloração de $G(V, A)$ é uma atribuição de alguma cor de $C$ para cada vértice de $V$, de tal modo que a dois vértices adjacentes de $\mathrm{G}$ sejam atribuídas cores diferentes.

Definição 36: Uma coloração de $G$ é uma função $f: V \rightarrow C$ tal que para cada par de vértices $v, w \in V$ tem-se $(v, w) \in A \Rightarrow f(v) \neq f(w)$.

Uma k-coloração de $G(V, A)$ é uma coloração que utiliza um total de k cores o que equivale a uma partição de V em k SCIE, maximais ou não. Diz-se então que G é k-colorível.

Definição 37: Denomina-se número cromático, $\lambda(G)$, de um grafo $G$, ao menor número de cores k, para o qual existe uma k-coloração de $\mathrm{G}$.

É muito fácil colorir um grafo de $n$ vértices: basta utilizar n cores, uma para cada vértice. Porém, o problema de se determinar um procedimento eficiente para realizar a coloração de um 
grafo com um número mínimo de cores é bastante complexo. Até o momento presente, não é conhecido algoritmo eficiente (Szwarcfiter,1983) para determinar o número cromático de um grafo. Entretanto, pode-se obter alguns resultados imediatos da definição, tais como:

i) Um grafo $G(V, A)$ é bicromático se e somente se for bipartido.

ii) Um grafo completo $K_{t}$ é t-cromático.

iii) Um grafo $\mathrm{G}(\mathrm{V}, \mathrm{A})$ com uma ou mais arestas é pelo menos 2-cromático.

Os conceitos de coloração, clique e conjunto independente de vértices (SCIE) estão naturalmente relacionados:

De fato, como são necessárias $\mathrm{k}$ cores para colorir os $\mathrm{k}$ vértices de uma clique de tamanho $\mathrm{k}$, isto implica que $\lambda(G)$ é maior ou igual ao tamanho da maior clique de $\mathrm{G}$. Considere agora uma k-coloração de $G(V, A)$. Sejam $V_{i}, V_{2}, \ldots, V_{k}$ os subconjuntos disjuntos de $V$ onde os vértices de $V_{1}, V_{2}, \ldots, V_{k}$ são coloridos com as cores $c_{1}, c_{2}, \ldots, c_{k}$, respectivamente. Então $\cup V_{i}=$ $\mathrm{V}, \mathrm{i}=1, \ldots, \mathrm{k}$ e cada $\mathrm{V}_{\mathrm{i}}$ é um conjunto independente de vértices (SCIE). Com isto, o problema de determinar uma coloração de $\mathrm{G}$ pode ser formulado em termos de particionar $\mathrm{V}$ em um número mínimo de SCIE (maximais ou não).

Definição 38: O número de estabilidade interna, $\alpha(G)$, de um grafo $G(V, A)$ é o número de vértices de um SCIE de maior cardinalidade do grafo. Na Figura 2.16, $\alpha(\mathrm{G})=2$.

Seja $G(V, A)$ um grafo não orientado com $|V|=n$ e $|A|=m$. Alguns resultados importantes unindo $\lambda(G)$ e $\alpha(G)$, m, n e ao grau máximo de $G$ são dados pelos teoremas:

(i) $\quad \lambda(\mathrm{G})+\alpha(\mathrm{G}) \leq \mathrm{n}+1$

(ii) Se $\bar{G}$ é o grafo complementar de $\mathrm{G}$ então $\lambda(\mathrm{G})+\lambda(\bar{G}) \leq \mathbf{n}+1$

(iii) $\quad \lambda(G) \geq n^{2} /\left(n^{2}-2 m\right)$

(iv) Se o grau máximo de $G$ é $h$ então $\lambda(G) \leq h+1$

(v) Um grafo é bicromático se e somente se não contém ciclos de comprimento ímpar.

Obs.: A demonstração desses teoremas podem ser encontradas em Netto (1979). 


\subsection{Aplicações}

Para ilustrar a aplicação dos estudos em coloração em grafos, apresentamos dois problemas. Outras aplicações são discutidas em Leigthon (1979), Opsut e Roberts (1981) e De Werra (1985).

\subsubsection{O problema dos exames escolares (Netto, 1979)}

Considera-se um conjunto $\mathrm{X}$ de provas a serem realizadas por um conjunto $\mathrm{Y}$ de estudantes onde cada prova $x \in X$ deve ser realizada por um conjunto $S(x)$ de estudantes. Cada prova deve ser aplicada uma única vez, o que determina o comparecimento de todos os alunos que devem realizá-la. Se cada aluno comparece no máximo a uma prova por dia, o problema consiste em se determinar o menor número de dias exigidos para a programação das provas. Pode-se resolver este problema construindo um grafo $G(X, U)$ no qual cada aresta $(x, y) \in U$ se $S(x) \cap S(Y) \neq \varnothing$, isto é, as provas $x$ e y não podem ser realizadas no mesmo momento, pois existem alunos que devem estar presentes em ambas. Cada coloração dos vértices corresponde a uma alocação possível de provas. As provas correspondentes a vértices de mesma cor poderão ser previstas para o mesmo dia. O número de dias necessários será, então, $\lambda(G)$.

\subsubsection{O problema do pensionato (Berge, 1976)}

Quinze moças que estudam em um pensionato saem para passear todos os dias dispostas em 3 filas. Pergunta-se: é possível realizar sete passeios consecutivos sem que duas moças estejam lado a lado mais de uma vez? Este é um problema clássico da teoria dos grafos e foi objeto de numerosos estudos. Trata-se de um problema próximo de outro igualmente célebre, o problema de Steiner, onde dispõe de 15 moças para formar 35 conjuntos distintos de modo que duas moças não façam parte do mesmo conjunto mais de uma vez.

A resolução do problema de Steiner pode ser feita através de um grafo G cujos vértices são os $\mathrm{C}_{15,3}=455$ conjuntos possíveis, dois conjuntos estando unidos por uma aresta se entre eles existir duas moças em comum. Desta forma, procura-se o "stable" S de cardinal máximo. Têm-se $|\mathrm{S}| \leq 35$, uma vez que em $\mathrm{S}$ a mesma moça aparece no máximo em 7 conjuntos distintos, o que representa um total de $15 \times 7 \times 1 / 3=35$ conjuntos no máximo. Para ver que uma solução 
Capítulo 2- Introdução à Teoria dos Grafos 30

do problema de Steiner, relaciona-se com o problema do pensionato, constrói-se um grafo $\mathrm{G}_{1}$ cujos vértices são os 35 conjuntos relacionados, dois conjuntos estando unidos por uma aresta se entre eles existir uma moça em comum. Se o número cromático $\lambda\left(\mathrm{G}_{1}\right)$ for igual a 7 , o problema está resolvido; se $\lambda\left(G_{1}\right)>7$, será necessário relacionar outros conjuntos de moças. 


\section{Capítulo 3. Algoritmos para Coloração dos Vértices de um Grafo}

Neste capítulo são apresentados alguns algoritmos e heurísticas para efetuar a coloração dos vértices de um grafo. Um destaque especial é dado à heuristica proposta por Guénoche (1993) que serve de base para a técnica de coloração em grafos utilizada no método que implementamos para auxiliar no projeto de células de manufatura.

\subsection{Heurísticas Seqüenciais}

Seja uma tabela $\mathrm{V}$ que define uma ordem qualquer de $\mathrm{N}$ vértices de $\mathrm{G}$. Um método seqüencial S consiste em colorir os vértices de $G$, dada uma ordenação inicial dos mesmos, atribuindo-se ao vértice a ser colorido a cor de menor índice não utilizada pelos seus vizinhos. Heurísticas deste tipo são chamadas de Gulosas ou Míopes diferenciando-se entre si somente pela regra de ordenação dos vértices. Esta classe pode ainda se subdividir em duas outras (Gouvêa, 1993):

- Seqüencial simples: constituída por heuristicas em que a ordenação inicial dos vértices permanece por toda a execução do algoritmo.

- Seqüencial dinâmica: constituída por heurísticas em que a ordenação pode ser modificada ou até mesmo constituída durante a execução do algoritmo considerado.

A classe dos grafos perfeitamente ordenáveis reúne todas as famílias de grafos para os quais é possível determinar regras de ordenação de vértices de forma que a heurística gulosa colore seus vértices de maneira ótima, como por exemplo, árvore de peso mínimo.

O primeiro algoritmo seqüencial foi implementado por Welsh e Powell (1967). A idéia geral da heurística é obter $\lambda(\mathrm{G})$, ou pelo menos uma boa aproximação, examinando os vértices em ordem não-crescente de seus vértices. Uma descrição deste algoritmo é feita abaixo e sua complexidade é $\mathrm{O}\left(\mathrm{n}^{2}\right)$. 


\section{Algoritmo de Welsh e Powell:}

\section{Inicio}

Dado $G(S, A)$, ordenar $S$ em ordem não-crescente de graus $x_{1}, \ldots, x_{n}$

$\mathrm{C}_{1} \leftarrow\left\{\mathrm{x}_{1}\right\}$

$\mathrm{C}_{\mathrm{i}} \leftarrow \varnothing, \mathrm{i}=2, \ldots, \mathrm{n}$

$$
\begin{aligned}
& \text { Para } \mathrm{j}=2 \text { até } \mathrm{n} \text { fazer } \\
& \mathrm{r} \leftarrow \min \left\{\mathrm{i} / \Gamma\left(\mathrm{x}_{\mathrm{j}}\right) \cap \mathrm{C}_{\mathrm{i}}=\varnothing\right\} \\
& \mathrm{C}_{\mathrm{r}} \leftarrow \mathrm{C}_{\mathrm{r}} \cup\left\{\mathrm{x}_{\mathrm{j}}\right\}
\end{aligned}
$$

\section{FimPara}

\section{Fim}

No pior caso, o desempenho deste algoritmo é muito ruim. A família de grafos apresentada a seguir foi sugerida por Johnson (1974): seja $G\left(S_{1} \cup S_{2}, A\right)$ um grafo bipartido com $\left|\mathrm{S}_{1}\right|=\left|\mathrm{S}_{2}\right|=\mathrm{n}$ e $|\mathrm{A}|=\mathrm{n}(\mathrm{n}-1)$ tal que $\forall \mathrm{x}_{\mathrm{i}} \in \mathrm{S}_{1}$ e $\mathrm{y}_{\mathrm{i}} \in \mathrm{S}_{2}$ tem-se $\Gamma\left(\mathrm{x}_{\mathrm{i}}\right) \cap\left\{\mathrm{y}_{\mathrm{i}}\right\}=\varnothing$ e $\Gamma\left(\mathrm{x}_{\mathrm{i}}\right)=\left\{\mathrm{y}_{1}, \ldots\right.$, $\left.\mathrm{y}_{\mathrm{i}-1}, \mathrm{y}_{\mathrm{i}+1}, \ldots, \mathrm{y}_{\mathrm{n}}\right\}$. Aplicando a heurística considerando a seqüência de vértices $\left\{\mathrm{x}_{1}, \mathrm{y}_{1}, \ldots, \mathrm{x}_{\mathrm{i}}, \mathrm{y}_{\mathrm{i}}, \ldots\right.$, $\left.x_{n}, y_{n}\right\}$, obtém-se $\lambda(G)=n$ sendo que para qualquer grafo bipartido, $\lambda(G)=2$. (Figura 3.1).
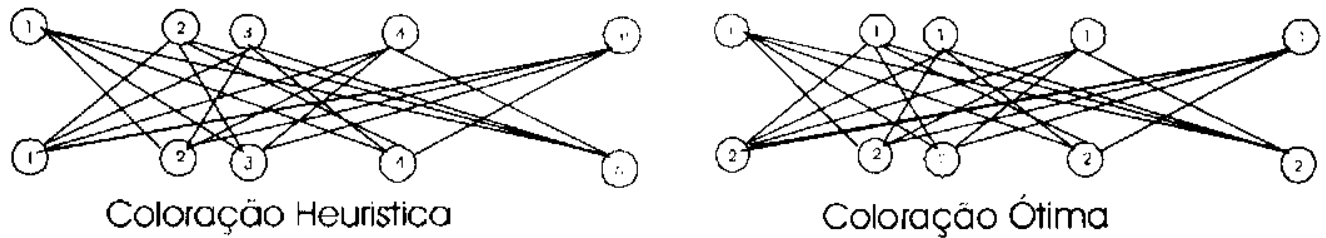

Figura 3. 1

As heurísticas seqüenciais dinâmicas exibem, em geral, resultados computacionais mais favoráveis, como por exemplo, podemos citar as heurísticas de Dsatur (Degree of Saturation), de Brélaz (1979) e RLF (Recursive Largest First) de Leighton (1979). Os dois algoritmos, citados acima, obtém resultados exatos para grafos bipartidos.

\subsubsection{A Heurística Dsatur}

Esta pode ser considerada uma heurística gulosa inspirada dos métodos seqüenciais. A cada iteração, define-se o grau de saturação $\operatorname{DS}_{\mathrm{i}}(\mathrm{x})$ como o número de cores já utilizadas pelos vizinhos de $\mathrm{x}$. A heurística Dsatur consiste em: a) colorir o vértice de maior grau com a cor 1 ; b) 
nas etapas seguintes, pegar o vértice livre de DS máximo e colori-lo com a cor de menor índice possível.

Este algoritmo pode ser considerado como um método seqüencial dinâmico, onde a ordem é constituída a cada iteração em vez de ser estabelecida a priori. Em cada iteração, os vértices coloridos formam um subgrafo conexo, pois um vértice de DS nulo não será pego enquanto existir vértices com DS $>0$.

O algoritmo de Dsatur, apresentado abaixo, tem complexidade $\mathrm{O}\left(\mathrm{n}^{2}\right)$.

\section{Algoritmo de Dsatur}

\section{Inicio}

$$
\begin{aligned}
& \mathrm{x}_{\mathrm{i}}=\text { vértice de maior grau em } \mathrm{G}(\mathrm{V}, \mathrm{A}) \\
& \lambda(\mathrm{G}) \leftarrow 1, \mathrm{C}_{1} \leftarrow\left\{\mathrm{x}_{1}\right\}, \mathrm{C}_{\mathrm{i}} \leftarrow \varnothing, \mathrm{i}=2, \ldots, \mathrm{n} \\
& \text { Para } \mathrm{j}=2 \text { até } n \text { fazer } \\
& \mathrm{x}_{\mathrm{j}} \leftarrow \text { vértice de maior grau de saturaçào em } \mathrm{G} \text {. } \\
& \mathrm{r} \leftarrow \text { grau de saturação de } \mathrm{v}_{1}+1 \\
& \mathrm{C}_{\mathrm{T}} \leftarrow \mathrm{C}_{\mathrm{r}} \cup\left\{\mathrm{x}_{\mathrm{j}}\right\}, \lambda(\mathrm{G}) \leftarrow \max \{\lambda(\mathrm{G}), \mathrm{r}\}
\end{aligned}
$$

\section{FimPara}

Fim.

Os algoritmos seqüenciais de coloração colorem os vértices em uma certa ordem. No algoritmo de Dsatur, parte-se de um vértice de grau máximo ao qual é atribuído a cor 1 . Todos os vértices que the são adjacentes estão "saturados" por esta cor. Define-se um índice de saturação para cada vértice não colorido igual ao número de cores diferentes ao qual ele é adjacente. A cada iteração escolhe-se colorir o vértice mais saturado e se houver empate, retém-se aquele que possui grau máximo no subgrafo parcial dos vértices não coloridos e este recebe a cor de menor índice.

\subsubsection{A Heurística RLF}

Abaixo é fornecida a heurística RLF. A atribuição de cores aos vértices é feita consolidando cada classe de coloração por vez através de um critério guloso. 


\section{Algoritmo RLF}

\section{Dados}

C: próxima classe de coloração a ser construída.

$\mathrm{V}$ : conjunto de vértices a colorir

Q: conjunto de vértices não coloridos os quais não podem receber a cor da classe C.

Gr: Grafo residual induzido pelos vértices não alocados em qualquer classe de coloração após a consolidação da classe C.

\section{Inicio}

$\mathrm{V} \leftarrow[1 . . \mathrm{n}]$ \{Inicialmente nenhum vértice está colorido $\}$

$\mathrm{G} \leftarrow \varnothing, \mathrm{k} \leftarrow 1$, pare $\leftarrow$ falso

Repita até pare $=$ verdadeiro

$\mathrm{C}[\mathrm{k}] \leftarrow \varnothing$

ConstrGs(GR, V); \{Construção do grafo residual Gr com os elementos de V\}

$\left\{\right.$ Escolher $v_{0} \in V:|\Gamma(v)|, v \in V$ no grafo residual $\left.G r\right\}$

$\mathrm{C}[\mathrm{k}] \leftarrow \mathrm{C}[\mathrm{k}] \cup\left\{\mathrm{v}_{\mathrm{o}}\right\}$,

$\mathrm{Q} \leftarrow \mathrm{Q} \cup\left\{\mathrm{v} \in \mathrm{Gr} / \Gamma\left(\mathrm{v}_{\mathrm{o}}\right) \cap \mathrm{V} \neq \varnothing\right\}$

$\mathrm{V} \leftarrow \mathrm{V}-\left\{\left\{\mathrm{v}_{\mathrm{o}}\right\} \cup \mathrm{Q}\right\}$;

Enquanto $V \neq \varnothing$ faça

$\left\{\right.$ Escolher $\mathrm{v}_{\mathrm{l}} \in \mathrm{V}: \mid \Gamma\left(\mathrm{v}_{\mathrm{l}}\right)=\max \{|\Gamma(\mathrm{v}) \cap \mathrm{Q}|$ no grafo residual $\left.\mathrm{GR}\}\right\}$

$$
\begin{aligned}
& \mathrm{C}[\mathrm{k}] \leftarrow\left\{\mathrm{C}[\mathrm{k}] \cup\left\{\mathrm{v}_{1}\right\}\right\} \\
& \mathrm{Q} \leftarrow \mathrm{Q} \cup\left\{\mathrm{u} \in \Gamma\left(\mathrm{v}_{1}\right) \cap \mathrm{V}\right\} \\
& \mathrm{V} \leftarrow \mathrm{V}-\left\{\left\{\mathrm{v}_{1}\right\} \cup \mathrm{Q}\right\}
\end{aligned}
$$

\section{FimEnquanto}

Se $((V=\varnothing)$ e $(Q=\varnothing))$ então pare « verdadeiro FimSe

\section{Senão}

$$
\mathrm{V} \leftarrow \mathrm{Q}, \mathrm{Q} \leftarrow \varnothing, \mathrm{k} \leftarrow \mathrm{k}+1
$$

\section{FimSe}

\section{FimRepita}

Fim 


\subsubsection{A Heurística de Guénoche}

Seja o problema de particionar um conjunto $\mathrm{V}$ de $\mathrm{n}$ objetos munidos de uma dissimilaridade, em um número $\mathrm{k}$, fixo, de classes tal que o diâmetro $\mathrm{d}(\mathrm{P})$ entre as classes seja mínimo. Este problema corresponde a construir um grafo de teto mínimo, $\mathrm{G}_{\mathrm{s}}$, subgrafo parcial de G(V,A), que seja k-colorivel, de acordo com o seguinte resultado (Hansen e Delattre, 1978): Existe uma $k$-partição de diâmetro inferior a $s \Leftrightarrow G_{s}$ é k-colorivel. Então, para construir uma $k$ partição de diâmetro mínimo é suficiente encontrar um teto mínimo tal que $G_{s}$ seja k-colorivel.

Para k=2, os algoritmos polinomiais de Rao (1971), Hubert (1974), Leclerc (1986) e Hansen e Jaumard (1987) enumeram todas as partições em duas classes de diâmetro mínimo. Um algoritmo de complexidade $O\left(\mathrm{n}^{2}\right)$ é proposto por Guénoche, baseado na bicoloração de uma árvore de peso máximo para construir uma bipartição de diâmetro mínimo.

Para k > 2, Hansen e Delattre (1978) demonstraram que o problema é NP-Completo. Eles propõem um algoritmo baseado em um método de coloração ótima de grafos teto sucessivos, adaptado a partir do algoritmo de Brown (1972) e constroem para cada valor de k uma só partição de diâmetro mínimo. Karchmer e Naor (1988) descrevem um algoritmo implementado com processamento paralelo.

A heurística de Guénoche (1993) enumera todas as partições em um número fixo de classes de diâmetro mínimo. Este se baseia na coloração de um grafo teto em k cores, cada cor definindo uma classe. Utiliza-se várias heurísticas para aproximar o diâmetro e enumera-se as partições de diâmetro mínimo unicamente no passo final.

A heuristica de Guénoche (1993) propõe uma modificação no Dsatur: a cada etapa, colore-se o mesmo vértice que seria colorido pelo Dsatur, mas, dá-se a este vértice mais saturado, a cor que satura o menor número de vértices não coloridos, insaturados por esta cor, deixando livre mais cores para os vértices que serão coloridos depois. A complexidade continuará a mesma.

Existem muitos outros algoritmos propostos na literatura para a resolução do problema enunciado $(k>2)$. Escolhemos o algoritmo de Guénoche (1993) para a realização de um estudo mais aprofundado devido à qualidade das soluções descritas na literatura (Santos, 1996), e principalmente, por este fornecer todas as partições de diâmetro mínimo existentes, o que é importante como ferramenta para o processo de tomada de decisão. 
Antes de descrever o algoritmo de Guénoche (1993) em detalhes, pode-se mostrar que este não é polinomial.

Proposição (Guénoche, 1993): O número máximo de partições de diâmetro mínimo de um

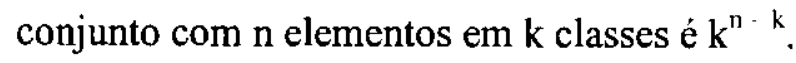

Demonstração: Considere um grafo completo com pesos nas arestas de $\mathrm{n}$ vértices cujas $\mathrm{k}(\mathrm{k}$ 1)/2 maiores arestas formam uma clique com $\mathrm{k}$ elementos. Se as k arestas seguintes (em ordem não-crescente) de valores iguais ao diâmetro entre as classes, $\mathrm{d}(\mathrm{P})$, ligam um mesmo vértice fora da clique a cada vértice da clique, este vértice e todos os outros podem ser inseridos em qualquer uma das classes que serão todas de diâmetro $d(P)$. Com isto, tem-se $k^{n-k}$ possibilidades.

\subsubsection{Matriz de Dissimilaridades e Partição}

Seja $V=\left\{v_{1}, v_{2}, \ldots, v_{n}\right\}$ um conjunto de $n$ objetos e $G(V, A)$ um grafo valorado, nãodirecionado, cujas arestas tem pesos fornecidos por uma matriz de pesos, $D=\left[d_{i j}\right]$, chamada matriz de dissimilaridades sobre $V$, tal que: $d_{i j}=\omega\left(x_{i}, x_{j}\right)=\omega\left(x_{j}, x_{i}\right) \geq 0$.

A dissimilaridade em questão mede as diferenças entre os objetos com relação a uma série de atributos considerados relevantes.

Seja $\left\{C_{1}, C_{2}, \ldots, C_{k}\right\}$ uma partição de $V$ em k classes $\Rightarrow C_{i} \cap C_{j}=\varnothing$ e $\cup C_{i}=V$.

Para comparar as partições construídas sobre $\mathrm{V}$, é definido:

- $\mathrm{d}\left(\mathrm{C}_{\mathrm{p}}\right)=\max \left\{\mathrm{d}_{\mathrm{ij}}\right.$, para $\left.\mathrm{x}_{\mathrm{i}}, \mathrm{x}_{\mathrm{j}} \in \mathrm{C}_{\mathrm{p}}\right\}$ isto é, o diâmetro de uma classe igual à maior dissimilaridade intra-classe.

- $d(P)=\max \left\{d\left(C_{p}\right), k=1, \ldots, p\right\}$ isto é, o diâmetro de uma partição igual ao maior diâmetro de suas classes.

\subsubsection{Etapas da Heurística}

Seja o problema da enumeração de todas as partições de um conjunto $\mathrm{V}$ em um número de classes $\mathbf{k}$, fixado, e de diâmetro d(P) minimo. Este problema corresponde a construir um grafo teto $G_{s}$ onde as arestas têm um comprimento superior a $d(P)$ e que seja k-colorível (Hansen e Delattre, 1978). No algoritmo de Guénoche (1993), um limite superior, s, para d(P) é determinado de maneira heurística. Em seguida, enumeram-se, as k-colorações para $\mathrm{G}_{\mathrm{s}}$. Enquanto existir ao menos uma k-coloração possível, decrementa-se o valor de s e uma nova 
iteração é processada. Quando o algoritmo pára, o teto obtido é igual ao diâmetro das partições restantes.

Para enumerar todas as possíveis partições de $\mathrm{X}$, em $\mathrm{k}$ classes de diâmetro mínimo, aplica-se este algoritmo constituído de 3 etapas e com complexidade $\mathrm{O}\left(\mathrm{k}^{\mathrm{N}-\mathrm{k}}\right)$ :

$1^{\text {a }}$ etapa - Obtenção do grafo teto Gs k-colorivel

$2^{\mathfrak{a}}$ etapa - Enumeração de todas as k-colorações de $\mathrm{G}_{\mathrm{s}}$

$3^{\mathbf{a}}$ etapa - Eliminação das partições que não são de diâmetro mínimo.

\section{$1^{2}$ etapa - Obtenção do grafo teto Gs k-colorível}

Utiliza-se um método heurístico para determinar o teto $s$, aproximação superior de $\mathrm{d}(\mathrm{P})$, tal que $\mathrm{G}_{\mathrm{s}}$ seja k-colorivel. $\mathrm{O}$ teto $\mathrm{s}$ é determinado por método de subdivisões dicotômicas do intervalo de variação das dissimilaridades. Para cada tentativa, utiliza-se uma heurística gulosa de coloração.

\section{$2^{n}$ etapa - Enumeração de todas as k-colorações de $\mathbf{G}_{\mathbf{s}}$}

Uma vez fixado o teto $\mathrm{s}$, enumera-se todas as colorações de $\mathrm{G}_{\mathrm{s}}$ em $\mathrm{k}$ cores. Com o auxilio do algoritmo de Dsatur, obtém-se uma clique, se possível máxima, de $\mathrm{G}_{\mathrm{s}}$, onde cada vértice é o representante de uma classe. Em seguida colore-se os outros vértices, segundo a ordem de saturação, de todas as maneiras possíveis. Se um vérticc é adjacente a vértices coloridos, estas cores não poderão ser utilizadas para colori-lo. Obtém-se, assim, todas as partições em k classes de diâmetro inferior a s.

$3^{\text {\# }}$ etapa - Eliminação das partições que não são de diâmetro mínimo.

Considera-se as arestas na ordem não-crescente dos valores de dissimilaridades a partir de s. Uma aresta pode ser inserida no grafo enquanto existir uma partição compatível, isto é, se a aresta liga vértices de classes diferentes. Cada aresta inserida elimina, assim, algumas partições obtidas anteriormente, se elas existirem. A primeira aresta que não puder ser inserida, uma vez que se o for não restariam mais partições compativeis, tem valor igual ao maior valor de 
dissimilaridade interclasse, $\mathrm{d}(\mathrm{P})$. As partições restantes são de diâmetro mínimo, para um número fixo de classes. Esta etapa é mais rápida se s é uma boa aproximação de $\mathrm{d}(\mathrm{P})$.

Obs.: As três etapas do algoritmo serão descritas com mais detalhes a seguir e na seção 2 apresentaremos um exemplo ilustrativo e faremos um breve comentário sobre o algoritmo na seção 3 .

\section{Obtenção do grafo teto $\mathrm{G}_{\mathrm{s}} \mathrm{k}$-colorivel}

Na primeira etapa, constrói-se um grafo teto k-colorivel cujas arestas são aquelas que apresentam valor superior ou igual ao valor de um teto $s$ a determinar. Para obter este valor de $s$ utiliza-se um método de subdivisão dicotômica e um método seqüencial de coloração, no caso, a heurística de Dsatur de Brélaz.

O algoritmo de subdivisão, fornecido a seguir, executa esta tarefa.

\section{Algoritmo de subdivisão}

\{Num_Cor = número de cores obtidas usando o algoritmo de Dsatur. $\}$

$\mathrm{dMin} \leftarrow \operatorname{Minimo}\left\{\mathrm{d}_{\mathrm{ij}},(\mathrm{i}, \mathrm{j}) \in \mathrm{A}\right\}$

$\mathrm{dMax} \leftarrow \operatorname{Máximo}\left\{\mathrm{d}_{\mathrm{ij}},(\mathrm{i}, \mathrm{j}) \in \mathrm{A}\right\}$

Enquanto $(\mathrm{dMax}-\mathrm{dMin})>2$ faça

$\mathrm{s} \leftarrow(\mathrm{dMin}+\mathrm{dMax}) / 2$

Construção de $\mathrm{G}_{\mathrm{s}}$ colorido por Dsatur

Se num_cor $\leq k$ então $d M a x \leftarrow s$ Senão $d M i n \leftarrow s$

Fimse

FimEnquanto

Fim

Enumeração das k-coloracōos de $\mathrm{G}_{\mathrm{S}}$

Dispõe-se agora de um grafo k-colorível com uma ordem sobre os vértices onde os primeiros coloridos com cores distintas formam uma clique, obtida pelo algoritmo de Dsatur: o primeiro vértice estando colorido, colore-se com uma nova cor um vértice que lhe seja adjacente, 
depois se existe um vértice adjacente a estes dois, este recebe uma nova cor. Se o cardinal NbQ desta clique é o número de cores obtidas no fim do algoritmo, esta coloração e ótima.

A clique obtida não é necessariamente máxima dado que, de um lado o problema é NPCompleto e de outro, um grafo k-cromático não possui necessariamente uma clique com $\mathrm{k}$ elementos.

Para construir todas as $k$-colorações de $G_{s}$, utiliza-se esta clique como inicialização do processo de enumeração. Desenvolve-se uma estrutura arborescente em largura, na qual cada vértice da árvore designa um vértice do grafo e uma cor associada a este vértice. Nesta arborescência, um caminho entre uma folha e a raiz é um início de uma coloração no qual um vértice só pode aparecer uma vez. Inicializa-se a arborescência por uma cadeia constituída dos $\mathrm{NbQ}$ vértices da clique $\mathrm{Cl}($.) tendo as cores $1,2, \ldots, \mathrm{NbQ}$. A cada iteração, prolonga-se todas as folhas de maior profundidade. Elas são todas associadas a um mesmo vértice i. Colore-se o vértice j que segue i na ordem de coloração. Para cada folha, retrocedendo-se na arborescência, marca-se as cores dos vértices (coloridos) adjacentes a j; estas cores estão proibidas para ele. Todas as outras cores iniciam uma nova folha da arborescência. Quando todos os vértices estão coloridos, todas as folhas e os caminhos associados da arborescência correspondem a colorações diferentes.

O grafo $\mathrm{G}_{\mathrm{s}}$ é codificado em uma matriz com $\mathrm{n}$ linhas, a i-ésima linha contendo a lista dos vértices adjacentes a $x_{i} . G(i, j)$ é o número do $j$-ésimo vértice adjacente a $x_{i}$.

A estrutura de dados utilizada, para a enumeração de todas as k-colorações de $\mathrm{G}_{s}$, é constituída de três vetores $\mathrm{V}, \mathrm{C}, \mathrm{P}$ indexados sobre os vértices da arborescência:

- V(i) contém o número de um vértice de $G_{s}$.

- C(i) contém a cor desse vértice.

- O índice $\mathrm{i}$ designa o i-ésimo vértice da arborescência.

- P(i) é o predecessor de i na arborescência.

- O vértice seguinte s na ordem de Dsatur é codificado Suc(s)

- O último vértice a colorir é chamado Der.

- p é o número de classes desejado.

O algoritmo, descrito a seguir, é o responsável pela construção e pela enumeração de todas as diferentes partições do grafo teto $\mathrm{G}_{\mathrm{s}}$ em $\mathrm{k}$ classes. 


\section{Algoritmo Enumeração das k-coloracões de diâmetro <s}

$\mathrm{i}_{1} \leftarrow \mathrm{NbQ}, \mathrm{i}_{2} \leftarrow \mathrm{NbQ}-\mathrm{s}$,

Para $\mathrm{i} \leftarrow 1$ a NbQ faça

$\mathrm{V}(\mathrm{i}) \leftarrow \mathrm{Cl}(\mathrm{i}), \mathrm{C}(\mathrm{i}) \leftarrow \mathrm{i}, \mathrm{P}(\mathrm{i}) \leftarrow \mathrm{i}-1$ \{somente os vértices da clique estão em classes\}

\section{FimPara}

Enquanto $i_{2} \neq \varnothing$ faça

$s \leftarrow V\left(i_{1}\right)$,

$\mathrm{v} \leftarrow \operatorname{Suc}(\mathrm{s}) \quad$ tenta-se colorir $\mathrm{s}\}$

Para $c \leftarrow 1$ até $p$ faça coul $(c) \leftarrow 0$ FimPara

$\mathrm{k} \leftarrow \mathrm{i}_{1}$

Enquanto $k \neq 0$ faça

$\mathrm{t} \leftarrow \mathrm{V}(\mathrm{k})$

Se $t \in \Gamma(v)$ então coul $(C(k)) \leftarrow 1$ FimSe

$\mathrm{k} \leftarrow \mathrm{P}(\mathrm{k})$

\section{FimEnquanto}

Para $\mathrm{c} \leftarrow 1$ até p faça

Se Coul $(c)=0$ então $\quad\{$ a cor c é possível $\}$

Se $v \neq$ Der então

$\mathrm{i}_{2} \leftarrow \mathrm{i}_{2}+1, \mathrm{~V}\left(\mathrm{i}_{2}\right) \leftarrow \mathrm{v}, \mathrm{C}\left(\mathrm{i}_{2}\right) \leftarrow \mathrm{c}, \mathrm{P}\left(\mathrm{i}_{2}\right) \leftarrow \mathrm{i}_{1}$

Senão $\operatorname{Coul}(v) \leftarrow c$ \{sai a partição\}

FimSe

FimSe

FimPara

\section{FimEnquanto}

Fim

Este algoritmo é de complexidade proporcional ao número de vértices e ao número de colorações em $k$ cores do grafo $G_{s}$ (Guénoche, 1993). Quanto menor o teto s, maior o número de arestas do grafo e menos colorações existem. É por isto que se toma tanto cuidado, através de uma busca dicotômica, em diminuir s para depois inserir arestas, sem se contentar com o primeiro teto que permita uma k-coloração. 


\section{Eliminação das partições que não são de diâmetro mínimo}

Até o momento, construiu-se todas as partições de diâmetro inferior ao teto $\mathrm{s}$ que se define o grafo $\mathrm{G}_{\mathrm{s}}$. Considera-se as arestas de comprimento inferior a s, em ordem não-crescente. Se para uma aresta $(i, j)$ existe ao menos uma partição tal que i e j não estejam na mesma classe, existe então uma partição de diâmetro $\mathrm{d}_{\mathrm{ij}}<\mathrm{s}$. Se todas as arestas de valor $\mathrm{d}_{\mathrm{ij}}$ satisfazem esta condição, as partições restantes são no máximo de diâmetro $\mathrm{d}_{\mathrm{ij}}<\mathrm{s}$.

Considera-se, então, todas as arestas de valor $\mathrm{d}(\mathrm{P})$ imediatamente inferior a s. Se existir ao menos uma partição compatível com estas arestas, todas as partições compatíveis têm diâmetro inferior a s; itera-se o procedimento fazendo $s \leftarrow \mathrm{d}(\mathrm{P})$ e armazenando-se apenas as partições compatíveis. Se nenhuma partição é compatível com todas as arestas de valor d(P), as partições restantes têm diâmetro $\mathrm{d}(\mathrm{P})$ e o algoritmo pára.

\subsection{Exemplo Ilustrativo}

Uma aplicação do algoritmo de Guénoche (1993) é apresentada a seguir. O exemplo ilustrativo (Santos, 1996) utiliza um conjunto, de 9 objetos, que se deseja particionar em 3 classes de modo que o diâmetro entre classes seja mínimo. A Tabela 3.1, abaixo, apresenta a matriz de dissimilaridades $\mathrm{D}$ entre os objetos.

\begin{tabular}{|c|c|c|c|c|c|c|c|c|c|}
\hline \multicolumn{10}{|c|}{ Matriz de dissimilaridades } \\
\hline & $\mathbf{1}$ & $\mathbf{2}$ & $\mathbf{3}$ & $\mathbf{4}$ & $\mathbf{5}$ & $\mathbf{6}$ & $\mathbf{7}$ & $\mathbf{8}$ & $\mathbf{9}$ \\
\hline $\mathbf{1}$ & 0 & & & & & & & & \\
\hline $\mathbf{2}$ & 17 & 0 & & & & & & & \\
\hline $\mathbf{3}$ & 49 & 3 & 0 & & & & & & \\
\hline $\mathbf{4}$ & 68 & 69 & 29 & 0 & & & & & \\
\hline $\mathbf{5}$ & 23 & 39 & 67 & 23 & 0 & & & & \\
\hline $\mathbf{6}$ & 12 & 63 & 3 & 44 & 6 & 0 & & & \\
\hline $\mathbf{7}$ & 73 & 38 & 89 & 56 & 71 & 81 & 0 & & \\
\hline $\mathbf{8}$ & 84 & 94 & 39 & 95 & 68 & 51 & 40 & 0 & \\
\hline $\mathbf{9}$ & 90 & 66 & 55 & 28 & 19 & 51 & 65 & 15 & 0 \\
\hline
\end{tabular}

Tabela 3.1

Aplica-se as três etapas do algoritmo sobre a matriz de dissimilaridades D. 


\section{$1^{\text {a }}$ Etapa:}

Dmax $=95$ e Dmin $=3$. Usando o algoritmo de subdivisão, obtém-se 4 cores para o teto 49, 2 cores para o teto 72,4 cores para o teto 60,3 cores para o teto 66,4 cores para o teto 63 e, finalmente, 3 cores para o teto 64 . A partição obtida para este teto é fornecida na Tabela 3.2 a seguir:

\begin{tabular}{|c|c|c|}
\hline Classe1 & Classe2 & Classe3 \\
\hline 7,8 & $1,2,3,6$ & $4,5,9$ \\
\hline
\end{tabular}

Tabela 3.2

A representação geométrica do grafo $G_{64}$, considerando a clique $\{7,1,9\}$ obtida no algoritmo de Dsatur, pode ser vista na Figura 3.1 abaixo.

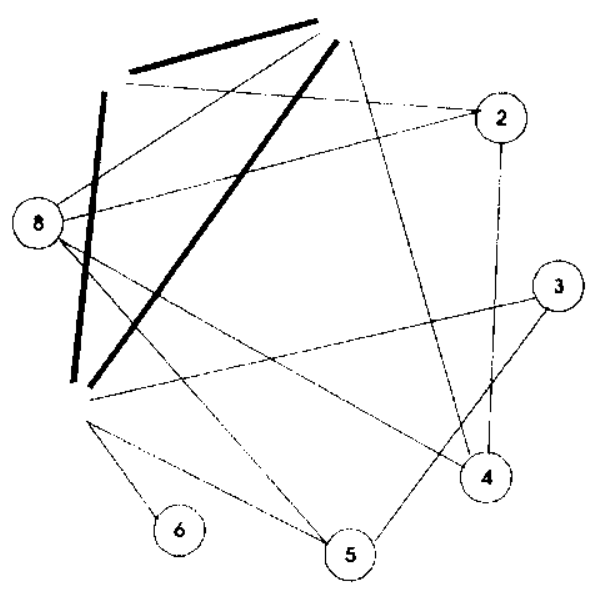

Figura 3.2

\section{$2^{\mathfrak{a}}$ Etapa:}

Utiliza-se a clique $\mathrm{Cl}=\{7,1,9\}$ para enumerar todas as possíveis colorações deste grafo em 3 cores, obtendo-se 6 partições de diâmetro estritamente inferior a 64. É fácil verificar que essas partições são as únicas existentes. A Tabela 3.3, fornecida a seguir, apresenta as 6 partições obtidas. 


\begin{tabular}{|c|c|c|c|}
\hline Partição & Classe 1 & Classe 2 & Classe3 \\
\hline $\mathbf{1}$ & 7,8 & $1,2,3$ & $4,5,6,9$ \\
\hline $\mathbf{2}$ & 7,8 & $\mathbf{1 , 2 , 3 , 6}$ & $4,5,9$ \\
\hline $\mathbf{3}$ & 7,8 & $1,2,5$ & $3,4,6,9$ \\
\hline $\mathbf{4}$ & 7,8 & $1,2,5,6$ & $3,4,9$ \\
\hline $\mathbf{5}$ & 4,7 & $1,2,5$ & $3,6,8,9$ \\
\hline $\mathbf{6}$ & 4,7 & $\mathbf{1 , 2 , 5 , 6}$ & $3,8,9$ \\
\hline
\end{tabular}

Tabela 3.3

A Figura 3.2 ilustra a obtenção das 6 partıçòes em 3 cores do grafo $G_{64}$ utilizando a matriz de adjacências do grafo (Tabela 3.4).

\begin{tabular}{|c|c|}
\hline \multicolumn{2}{|c|}{ Grafo $\mathbf{G}_{\mathbf{6 4}}$} \\
\hline Vértices & Adjacências \\
\hline & $4,, 8,9$ \\
\hline 2 & $4,8,{ }^{9}$ \\
\hline 3 & 5, \\
\hline 4 & $, 2,8$ \\
\hline 5 & $3,, 8$ \\
\hline 6 & - \\
\hline & $, 3,5,6,9$ \\
\hline 8 & $, 2,4,5$ \\
\hline 9 &, 2, \\
\hline
\end{tabular}

Tabela 3.4

Figura 3.3 


\section{3a Etapa:}

Nesta etapa, ordena-se as arestas em ordem não-crescente de dissimilaridades cujo valor seja inferior ao teto $s=64$, obtendo-se:

$(2,6) /(4,7) /(3,9) /(6,8),(6,9) /(1,3) /(4,6) /(7,8) /(2,5),(3,8) /(2,7) /(3,4) /(4,9) /(1,5),(4,5) /$ $(5,9) /(1,2) /(8,9) /(1,6) /(5,6) /(2,3),(3,6)$

Examina-se as arestas de comprimento imediatamente inferior a s: $(2,6)$ de valor 63 que é compatível com a primeira, terceira e quinta partições. Com isto, elimina-se a segunda, quarta e sexta partições. Examina-se a aresta $(4,7)$ de valor 56 que é compatível com a primeira e terceira partição. A quinta partição é, então, eliminada. A próxima aresta, $(3,9)$, só é compatível com a primeira partição.

Examina-se as arestas $(6,8)$ e $(6,9)$, de valor 51: a aresta $(6,8)$ é compativel com a primeira partição mas $(6,9)$ não. Com isto, a partição restante tem diâmetro igual a 51 e é a única existente: o vértice $\mathrm{x}_{3}$ está necessariamente na classe de $\mathrm{x}_{1}$ assim como $\mathrm{x}_{4}$ está na classe de $\mathrm{x}_{9} \mathrm{o}$ que obriga $x_{8}$ a estar na classe de $x_{7}$ e $x_{2}$ a estar na classe de $x_{1}$. Com isto, o vértice $x_{6}$ vai para a classe de $x_{9}$.

A Tabela 3.5 fornece a partição resultante e a Figura 3.3 apresenta uma representação geométrica do grafo $\mathrm{G}_{55}$ com a única 3-coloração possível para o mesmo.

\begin{tabular}{|c|c|c|}
\hline Classe I & Classe2 & Classe3 \\
\hline 7,8 & $1,2,3$ & $4,5,6,9$ \\
\hline
\end{tabular}

Tabela 3.5

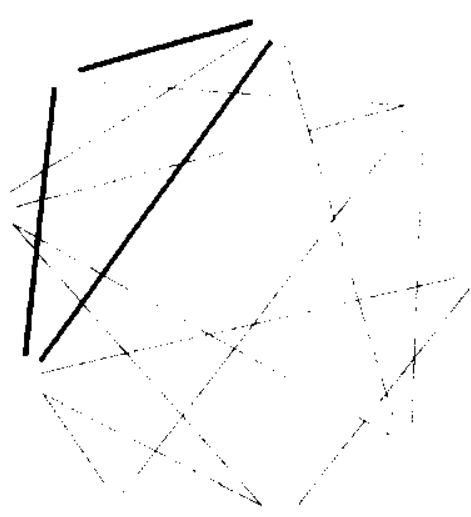

Figura 3.4

O teto obtido, $\mathrm{s}=55$, é o mínimo, pois para $\mathrm{s}=51\left(\mathrm{G}_{55}=\mathrm{G}_{54}=\mathrm{G}_{53}=\mathrm{G}_{52}\right)$, o grafo será 4-cromático (Figura 3.4). 


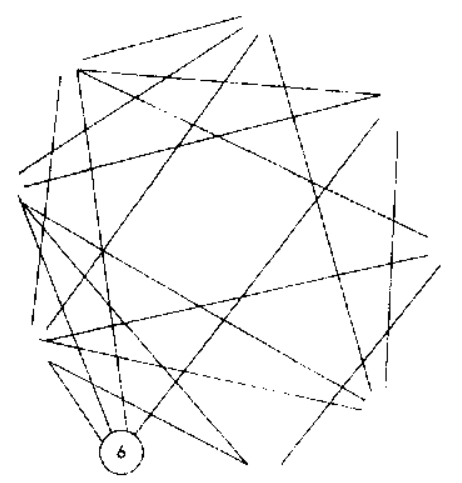

Figura 3.5

\subsection{Comentários}

Com o objetivo de efetuar o projeto de células de manufatura com o auxílio de coloração em grafos implementamos uma heurística baseada no método de Guénoche (1993). A idéia geral da heurística nas duas versões é a mesma e pode ser dividida em três etapas:

$1^{\text {a }}$ etapa - Obtenção do grafo teto $\mathrm{G}_{\mathrm{s}} \mathrm{k}$-colorível.

$2^{\mathrm{a}}$ etapa - Enumeração de todas as k-colorações de $\mathrm{G}_{\mathrm{s}}$.

$3^{\text {a }}$ etapa - Eliminação das partições que não são de diâmetro mínimo. 


\section{Capítulo 4. Coloração e Projeto de Células de Manufatura}

Neste capítulo apresentamos um estudo detalhado do método desenvolvido nesta dissertação para decomposição de sistemas de produção em células de manufatura desenvolvido com base em técnicas de coloração dos vértices de um grafo.

\subsection{Dados do problema}

Para iniciar o método de particionamento em células proposto e a subseqüente programação das tarefas a executar é necessário colher do sistema de produção os seguintes dados:

- os roteiros de fabricação das peças;

- a duração das operações feitas pelas máquinas sobres as peças;

- quantidade a ser produzida de cada peça.

\subsection{Algoritmo}

O algoritmo correspondente ao método proposto é constituido de quatro passos fundamentais:

$1^{\circ}$ - Determinação da matriz de cargas de trabalho;

$\mathbf{2}^{\mathbf{0}}$ - Computação das dissimilaridades cntre as peças;

$3^{0}$ - Enquanto o número desejado de células não for obtido fazer:

- Efetuar a coloração do grafo $\mathrm{G}(\mathrm{V}, \mathrm{A})$;

- Obter as famílias de peças;

Fim Enquanto.

$4^{0}$ - Obtenção dos grupos de máquinas. 


\subsubsection{Matriz de Cargas de Trabalho}

A partir dos dados iniciais obtém-se uma matriz [peças $\mathrm{x}$ máquinas], que fornece o tempo total que cada peça gasta na passagem em cada máquina do seu roteiro. Esta matriz é chamada de matriz de cargas de trabalho e seus coeficientes são calculados da seguinte maneira:

$$
\begin{array}{r}
\operatorname{carga}[\mathrm{i}, \mathrm{j}]=\text { unidade[i] } \\
* \sum \operatorname{duração[i,k]} \\
\mathrm{k} \mid \operatorname{roteiro}[\mathrm{i}, \mathrm{k}]=\mathrm{j}
\end{array}
$$

onde

unidade[i] = número de unidades da peça[i] a fabricar.

duração[i,k] = duração da operação $k$ sobre a peça[i] .

roteiro[i,k] = tipo de máquina utilizada para executar a operação $\mathrm{k}$ sobre a peça[i].

\subsubsection{Computação das Dissimilaridades}

O método de computação das dissimilaridades entre peças adotado no método proposto leva em consideração as diferenças existentes entre os roteiros de fabricação das peças. Dada a peça $P_{i}$ definida pelo vetor $0 / 1$ abaixo:

$$
P_{i}=\left[a_{i 1}, a_{i 2}, \ldots, a_{i k}, \ldots, a_{i m}\right]
$$

onde

$$
\begin{aligned}
& \mathrm{m}=\text { é o número de máquinas disponiveis } \\
& \mathrm{a}_{\mathrm{ik}}=\left\{\begin{array}{l}
1 \text { se a peça } \mathrm{i} \text { sofrer operação na máquina } \mathrm{k} \\
0 \text { caso contrário }
\end{array}\right.
\end{aligned}
$$

Denota-se por $d\left[P_{i}, P_{j}\right]$ a dissimilaridade entre as peças $P_{i}$ e $P_{j}$ e esta é dada por:

$$
\mathrm{d}\left[\mathrm{P}_{\mathrm{i}}, \mathrm{P}_{\mathrm{j}}\right]=\sum_{k=1}^{m} \Psi\left[\mathrm{a}_{\mathrm{ik}}, \mathrm{a}_{\mathrm{jk}}\right]
$$

onde 


$$
\Psi\left[a_{i k}, a_{j k}\right]=\left\{\begin{array}{l}
\alpha \text { se } a_{i k} \neq a_{j k} \\
\beta \text { se } a_{i k}=a_{j k}=0 \\
\gamma \text { se } a_{i k}=a_{j k}=1
\end{array}\right.
$$

A escolha dos parâmetros $\alpha, \beta$ e $\gamma$ é feita pelo usuário, com o objetivo de dar maior flexibilidade na obtenção das soluções (Ribeiro e Pradin, 1993).

\subsubsection{Decomposição do Sistema de Manufatura}

Após a obtenção das matrizes de cargas de trabalho e de dissimilaridades, é realizada a decomposição do sistema de manufatura da seguinte maneira:

- construção e coloração do grafo correspondente ao sistema de produção;

- obtenção das famílias de peças;

- obtenção dos grupos de máquinas.

\subsubsection{Construção e coloração do grafo}

O algoritmo utilizado no método proposto para construir e colorir o grafo teto é um algoritmo baseado na técnica de coloração de Guénoche (1993), que utiliza a coloração Dsatur: inicia-se a construção do grafo teto pela peça de grau máximo, atribuindo-lhe uma cor qualquer. A peça que possui o maior valor de dissimilaridade com a peça escolhida inicialmente será a próxima a ser colorida e receberá uma cor diferente da cor atribuída à peça inicial. O processo continua escolhendo a peça que possui a maior dissimilaridade entre a peça inicial e a segunda peça escolhida e assim sucessivamente. Dispondo-se assim de um grafo p-colorivel com uma ordem sobre as peças onde as primeiras peças coloridas com cores distintas formam uma clique.

Para construir todas as k-colorações do grafo teto, utiliza-se esta clique como inicialização do processo de enumeração. Desenvolve-se uma estrutura arborescente em largura, na qual cada vértice da árvore corresponde a um vértice do grafo e uma cor associada a este vértice. A cada iteração, prolonga-se todas as folhas. Elas são todas associadas a um mesmo vértice i. Colore-se o vértice j que segue na ordem de coloração. Para cada folha, retrocedendo-se na arborescência, marca-se as cores dos vértices coloridos adjacentes a $j$; estas cores estão proibidas para ele. Todas as outras cores iniciam uma nova folha da arborescência. No final do processo todos os vértices 
estarão coloridos e todas as folhas e os caminhos associados da arborescência correspondem a colorações diferentes.

Na primeira etapa da heurística proposta por Guénoche (1993), ao se obter o teto s, faz-se uma fase de otimização do teto: considera-se as arestas em ordem não-crescente, de comprimento imediatamente inferior a s. Seja $(i, j)$ esta aresta:

- Se i e j estão em classes diferentes, insere-se (i, j) a $\mathrm{G}_{\mathrm{s}}$ (condição $l$ ).

- Se (i,j) liga vértices de uma mesma classe, tenta-se colocar i ou j em uma outra classe sem aumentar o diâmetro. Sendo isto possível, insere-se $(i, j)$ a $\mathrm{G}_{\mathrm{s}}$ (condição 2).

\subsubsection{Obtenção das famílias de peças}

O método é iterativo e na primeira iteração as peças são particionadas em famílias através da enumeração das k-colorações do grafo teto. Todas as partições (ou seja, as famílias de peças) construídas são de diâmetro inferior ao teto s que define o grafo teto. Considera-se todas as arestas de valor d(P) imediatamente inferior a s. Se existir ao menos uma partição compatível com estas arestas, todas as partições compatíveis tem diâmetro inferior a s; itera-se o procedimento fazendo $\mathrm{s} \leftarrow \mathrm{d}(\mathrm{P})$ e armazenando apenas as partições compatíveis.

As peças que no processo de construção do grafo puderem ser atribuídas às famílias distintas por apresentar empate no valor de dissimilaridade, não são atribuídas a nenhuma delas em um primeiro momento. Após ter-se obtido todas as famílias de peças desejadas, faz-se uma varredura, onde as peças que ainda não pertencem a nenhuma família, são então atribuídas à família que possuir a menor dissimilaridade com estas.

\subsubsection{Obtenção dos grupos de máquinas}

Uma vez realizada a coloração do grafo e obtidas as famílias de peças, realiza-se a atribuição das máquinas às famílias projetadas. Esta atribuição é feita segundo o número de operações realizadas pelas máquinas em cada uma das famílias. Uma máquina será sempre atribuída à família onde executar o maior número de operações. O par [familia de peças x grupo de máquinas] constitui a célula de manufatura. 


\subsection{Exemplo ilustrativo}

O exemplo considerado para ilustrar o procedimento passo a passo é apresentado na Tabela 4.1 (Chan e Milner, 1981). Esta Tabela fornece os roteiros de fabricaçăo das peças e duração das operações de um sistema de produção composto de 10 peças e 15 máquinas. Deve-se particioná-lo em 3 células de manufatura. A Tabela 4.2 fornece a matriz de cargas de trabalho [peças $\mathrm{x}$ máquinas]. A Tabela 4.3 apresenta a matriz de dissimilaridades entre as peças. A Tabcla 4.4 mostra a contagem do número de operações realizadas pelas máquinas em cada uma das famílias formadas no processo de coloração e a Tabela 4.5 as células de manufatura projetadas.

\begin{tabular}{|c|c|l|l|}
\hline Peças & \multicolumn{1}{|c|}{ Unidades } & \multicolumn{1}{|c|}{ Roteiro } & \multicolumn{1}{|c|}{ Duração } \\
\hline 1 & 1 & 2101112 & 1111 \\
\hline 2 & 1 & 3581315 & 11111 \\
\hline 3 & 1 & 16914 & 1111 \\
\hline 4 & 1 & 14914 & 1111 \\
\hline 5 & 1 & 3581315 & 11111 \\
\hline 6 & 1 & 146914 & 11111 \\
\hline 7 & 1 & 7101112 & 1111 \\
\hline 8 & 1 & 3581315 & 11111 \\
\hline 9 & 1 & 46914 & 1111 \\
\hline 10 & 1 & 27101112 & 11111 \\
\hline
\end{tabular}

Tabela 4. 1 Roteiros de fabricação e duração das peças

\begin{tabular}{|c|c|c|c|c|c|c|c|c|c|c|c|c|c|c|c|}
\hline & 1 & 2 & 3 & 4 & 5 & 6 & 7 & 8 & 9 & 10 & 11 & 12 & 13 & 14 & 15 \\
\hline 1 & 0 & 1 & 0 & 0 & 0 & 0 & 0 & 0 & 0 & 1 & 1 & 1 & 0 & 0 & 0 \\
\hline 2 & 0 & 0 & 1 & 0 & 1 & 0 & 0 & 1 & 0 & 0 & 0 & 0 & 1 & 0 & 1 \\
\hline 3 & 1 & 0 & 0 & 0 & 0 & 1 & 0 & 0 & 1 & 0 & 0 & 0 & 0 & 1 & 0 \\
\hline 4 & 1 & 0 & 0 & 1 & 0 & 0 & 0 & 0 & 1 & 0 & 0 & 0 & 0 & 1 & 0 \\
\hline 5 & 0 & 0 & 1 & 0 & 1 & 0 & 0 & 1 & 0 & 0 & 0 & 0 & 1 & 0 & 1 \\
\hline 6 & 1 & 0 & 0 & 1 & 0 & 1 & 0 & 0 & 1 & 0 & 0 & 0 & 0 & 1 & 0 \\
\hline 7 & 0 & 0 & 0 & 0 & 0 & 0 & 1 & 0 & 0 & 1 & 1 & 1 & 0 & 0 & 0 \\
\hline 8 & 0 & 0 & 1 & 0 & 1 & 0 & 0 & 1 & 0 & 0 & 0 & 0 & 1 & 0 & 1 \\
\hline 9 & 0 & 0 & 0 & 1 & 0 & 1 & 0 & 0 & 1 & 0 & 0 & 0 & 0 & 1 & 0 \\
\hline 10 & 0 & 1 & 0 & 0 & 0 & 0 & 1 & 0 & 0 & 1 & 1 & 1 & 0 & 0 & 0 \\
\hline
\end{tabular}

Tabela 4. 2: Matriz de cargas de trabalho [peças $x$ máquinas] 


\begin{tabular}{|c|cccccccccc|}
\hline & 1 & 2 & 3 & 4 & 5 & 6 & 7 & 8 & 9 & 10 \\
\hline 1 & 0 & 9 & 8 & 8 & 9 & 9 & 1 & 9 & 8 & 1 \\
2 & 9 & 0 & 9 & 9 & 0 & 10 & 10 & 0 & 9 & 10 \\
3 & 8 & 9 & 0 & 2 & 9 & 1 & 9 & 9 & 2 & 9 \\
4 & 8 & 9 & 2 & 0 & 9 & 1 & 9 & 9 & 2 & 9 \\
5 & 9 & 0 & 9 & 9 & 0 & 10 & 10 & 0 & 9 & 10 \\
6 & 9 & 10 & 1 & 1 & 10 & 0 & 10 & 10 & 1 & 10 \\
7 & 1 & 10 & 9 & 9 & 10 & 10 & 0 & 10 & 9 & 0 \\
8 & 9 & 0 & 9 & 9 & 0 & 10 & 10 & 0 & 9 & 10 \\
9 & 8 & 9 & 2 & 2 & 9 & 1 & 9 & 9 & 0 & 9 \\
10 & 1 & 10 & 9 & 9 & 10 & 10 & 0 & 10 & 9 & 0 \\
\hline
\end{tabular}

Tabela4. 3: Matriz de dissimilaridades [peças $\mathrm{x}$ peças]

Para o cálculo desta matriz de dissimilaridades foi usado os parâmetros $\alpha=1, \beta=0$ e $\gamma=0$

\begin{tabular}{|c|c|c|c|}
\hline Máquinas & Família 1 & Família 2 & Família 3 \\
\hline 1 & 0 & 0 & 3 \\
2 & 2 & 0 & 0 \\
3 & 0 & 3 & 0 \\
4 & 0 & 0 & 3 \\
5 & 0 & 3 & 0 \\
6 & 0 & 0 & 3 \\
7 & 2 & 0 & 0 \\
8 & 0 & 3 & 0 \\
9 & 0 & 0 & 4 \\
10 & 3 & 0 & 0 \\
11 & 3 & 0 & 0 \\
12 & 3 & 0 & 0 \\
13 & 0 & 3 & 0 \\
14 & 0 & 0 & 4 \\
15 & 0 & 3 & 0 \\
\hline
\end{tabular}

Tabela 4. 4: Número de execuções executadas pelas máquinas em cada família 


\begin{tabular}{|c|c|c|c|c|c|c|c|c|c|c|c|c|c|c|c|}
\hline & 3 & 5 & 8 & 13 & 15 & 2 & 7 & 10 & 11 & 12 & 1 & 4 & 6 & 9 & 14 \\
\hline 2 & 1 & 1 & 1 & 1 & 1 & 0 & 0 & 0 & 0 & 0 & 0 & 0 & 0 & 0 & 0 \\
\hline 5 & 1 & 1 & 1 & 1 & 1 & 0 & 0 & 0 & 0 & 0 & 0 & 0 & 0 & 0 & 0 \\
\hline 8 & 1 & 1 & 1 & 1 & 1 & 0 & 0 & 0 & 0 & 0 & 0 & 0 & 0 & 0 & 0 \\
\hline 1 & 0 & 0 & 0 & 0 & 0 & 1 & 0 & 1 & 1 & 1 & 0 & 0 & 0 & 0 & 0 \\
\hline 7 & 0 & 0 & 0 & 0 & 0 & 0 & 1 & 1 & 1 & 1 & 0 & 0 & 0 & 0 & 0 \\
\hline 10 & 0 & 0 & 0 & 0 & 0 & 1 & 1 & 1 & 1 & 1 & 0 & 0 & 0 & 0 & 0 \\
\hline 3 & 0 & 0 & 0 & 0 & 0 & 0 & 0 & 0 & 0 & 0 & 1 & 0 & 1 & 1 & 1 \\
\hline 4 & 0 & 0 & 0 & 0 & 0 & 0 & 0 & 0 & 0 & 0 & 1 & 1 & 0 & 1 & 1 \\
\hline 6 & 0 & 0 & 0 & 0 & 0 & 0 & 0 & 0 & 0 & 0 & 1 & 1 & 1 & 1 & 1 \\
\hline 9 & 0 & 0 & 0 & 0 & 0 & 0 & 0 & 0 & 0 & 0 & 0 & 1 & 1 & 1 & 1 \\
\hline
\end{tabular}

\section{Tabela 4. 5: células de manufatura}

O primeiro passo do procedimento foi a construção do grafo teto $G_{s}$, onde $s=5$.

Na primeira iteração as seguintes famílias:

Família $1=\{2,5,8\}$

Familia $2=\{1,3,4,6,7,10\}$

A peça 9 não será atribuída inicialmente a nenhuma família pois poderia estar em qualquer uma delas.

A familia 1 tem diâmetro 0 e a familia 2 tem diâmetro 9. Escolhe-se, então, a família 2. Constrói-se em seguida um novo grafo teto $G_{\mathrm{s}}$ para esta família, obtendo-se a seguinte partição:

Família $2.1=\{1,7,10\}$

Família $2.2=\{3,4,6\}$

A peça 9 será atribuída a família 2.2, pois são com as peças atribuídas a esta família que a peça 9 possui menor dissimilaridade (igual a zero). 
As três famílias obtidas são:

Família $1=\{2,5,8\}$

Família $2=\{1,7,10\}$

Família $3=\{3,4,6,9\}$

Computando-se o número de operações de cada uma das máquinas nas famílias de peças, obtém-sc os seguintes grupos:

$$
\begin{aligned}
& \text { Grupo } 1=\{3,5,8,13,15\} \\
& \text { Grupo } 2=\{2,7,10,11,12\} \\
& \text { Grupo } 3=\{1,4,6,9,14\}
\end{aligned}
$$

A Figura 4.1 ilustra o sistema de produção particionado em três células de manufatura, pelo método proposto nesta dissertação.
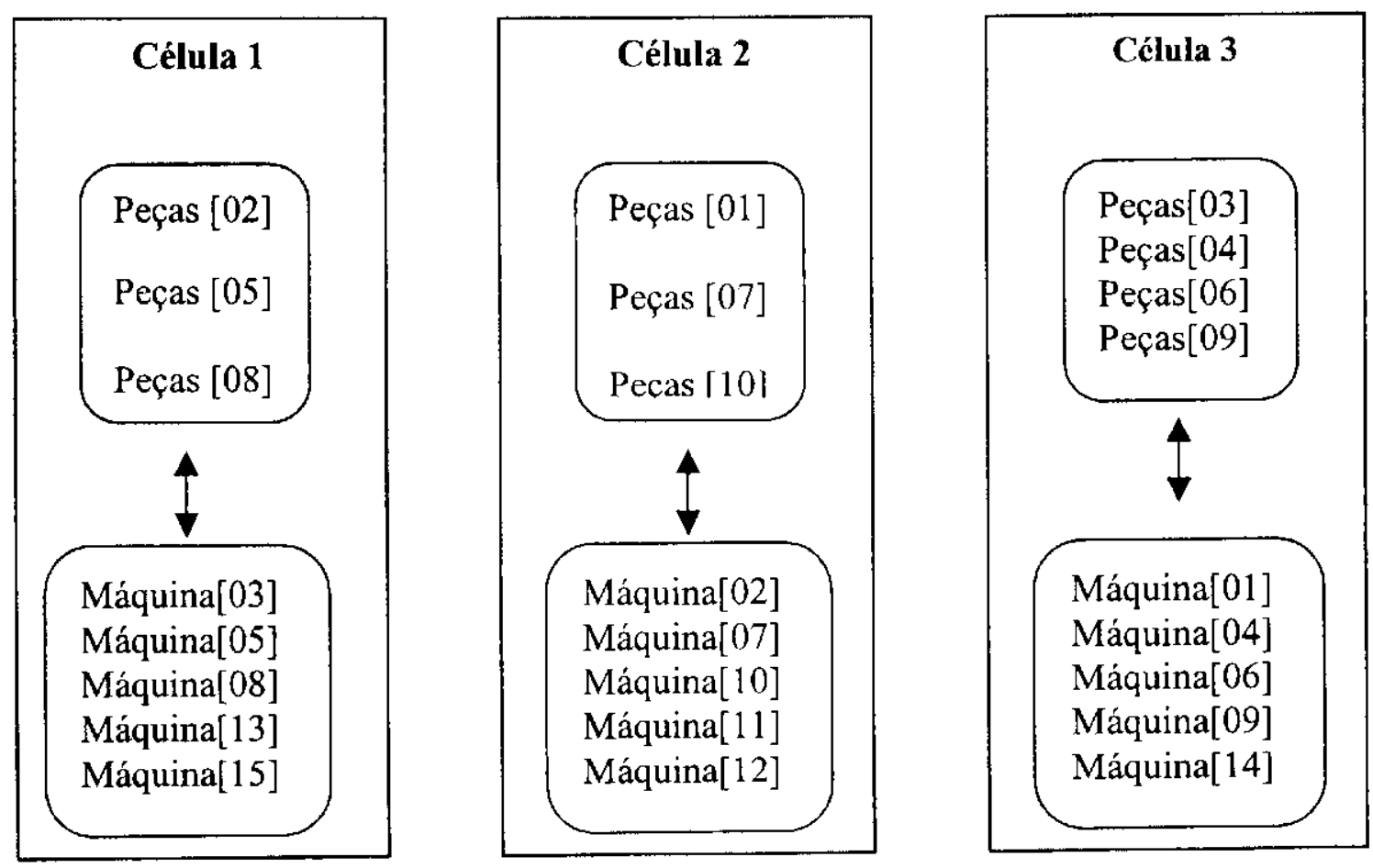

Figura 4.1

A solução obtida não apresenta movimentos inter-células, ou seja, os agrupamentos são independentes. Este resultado coincide com o resultado apresentado na literatura (Chan e Milner, 1981). 


\subsection{Aplicações}

Efetuamos alguns testes com o algoritmo proposto, com o objetivo de testar a sua eficiência, comparando com os resultados encontrados na literatura. O programa correspondente foi escrito em linguagem Delphi e está implementado em microcomputador.

$1^{\circ}$ - No exemplo de Kusiak (1987) particiona-se um sistema de produção formado por cinco peças e quatro máquinas $\mathrm{cm}$ duas células de manufatura. O resultado obtido não apresenta movimentos inter-células. Esse sistema é fornecido na Tabela 4.6.

Aplicando o algoritmo proposto no sistema acima, obtemos o mesmo resultado proposto pelo autor, que se encontra na Tabela 4.7.

\begin{tabular}{|c|c|cc|cc|}
\hline Peças & Unidades & \multicolumn{2}{|c|}{ Roteiro } & \multicolumn{2}{|c|}{ Duração } \\
\hline 1 & 1 & 2 & 4 & 1 & 1 \\
\hline 2 & 1 & 1 & 3 & 1 & 1 \\
\hline 3 & 1 & 2 & 4 & 1 & 1 \\
\hline 4 & 1 & 1 & 3 & 1 & 1 \\
\hline 5 & 1 & 1 & & 1 \\
\hline
\end{tabular}

Tabela 4. 6

\begin{tabular}{|l|llll|}
\hline & 2 & 4 & 1 & 3 \\
\hline 1 & & & & \\
3 & 1 & 1 & 0 & 0 \\
& 1 & 1 & 0 & 0 \\
2 & 0 & 0 & 1 & 1 \\
4 & 0 & 0 & 1 & 1 \\
5 & 0 & 0 & 1 & 0 \\
\hline
\end{tabular}

Tabela 4. 7 
$2^{\circ}$ - No exemplo de Waghodekar e Sahu (1984) particiona-se um sistema de produção constituído de sete peças e cinco máquinas em duas células de manufatura. $\mathrm{O}$ resultado obtido apresenta dois movimentos inter-células. Esse sistema é fornecido pela Tabela 4.8.

\begin{tabular}{|c|c|ccc|ccc|}
\hline Peças & Unidades & \multicolumn{2}{|c|}{ Roteiro } & \multicolumn{3}{|c|}{ Duração } \\
\hline 1 & 1 & 3 & 4 & 1 & 1 \\
\hline 2 & 1 & 1 & 3 & 1 & 1 \\
\hline 3 & 1 & 2 & 4 & 5 & 1 & 1 & 1 \\
\hline 4 & 1 & 1 & 3 & 5 & 1 & 1 & 1 \\
\hline 5 & 1 & 2 & 5 & & 1 & 1 \\
\hline 6 & 1 & 4 & 5 & & 1 & 1 \\
\hline 7 & 1 & 1 & 3 & 1 & 1 \\
\hline
\end{tabular}

Tabela 4.8

Utilizando o algoritmo proposto obtemos o mesmo resultado fornecido pelo autor, que se encontra na Tabela 4.9. Esta solução apresenta 2 movimentos inter-células.

\begin{tabular}{|l|lllll|}
\hline & 1 & 3 & 2 & 4 & 5 \\
\hline 1 & & & & & \\
2 & 1 & 0 & 1 & 0 \\
4 & 1 & 1 & 0 & 0 & 0 \\
7 & 1 & 1 & 0 & 0 & 1 \\
& 1 & 1 & 0 & 0 & 0 \\
3 & 0 & 0 & 1 & 1 & 1 \\
5 & 0 & 0 & 1 & 0 & 1 \\
6 & 0 & 0 & 1 & 1 \\
\hline
\end{tabular}

Tabela 4.9 
A Tabela 4.10 resume outros 13 testes realizados sobre exemplos clássicos extraídos da literatura. Os exemplos na Tabela estão indicados pelo número de referência da literatura que aparece enumerado na Tabela 4.11. A Tabela 4.10 apresenta a solução da literatura e a solução obtida pelo PROCECO (Programa para o Projeto de Células por Coloração) desenvolvido neste trabalho. Os resultados obtidos provocaram diminuição do número de movimentos inter-células (m.i.c) para os três primeiros exemplos da Tabela 4.10, ao mesmo tempo em que as dimensões das células continuaram as mesmas ou praticamente as mesmas da melhor solução até então conhecida. Para outros exemplos, obteve-se sempre resultados iguais ou equivalentes.

\begin{tabular}{|c|c|c|c|c|c|c|c|}
\hline & Exemplo & Solução & $\begin{array}{l}\text { Número de } \\
\text { células }\end{array}$ & $\begin{array}{l}\text { [peças } x \text { tipos } \\
\text { de máquinas] }\end{array}$ & $\begin{array}{c}\text { [peças } \mathrm{x} \\
\text { máquinas] }\end{array}$ & m.i.c. & $\begin{array}{c}\text { Dimensão das } \\
\text { células }\end{array}$ \\
\hline 1 & 1 & $\begin{array}{c}1 \\
\text { PROCECO }\end{array}$ & 2 & $9 \times 7$ & $9 \times 12$ & $\begin{array}{l}4 \\
2\end{array}$ & $\begin{array}{l}4 \times 6,5 \times 6 \\
4 \times 6,5 \times 6\end{array}$ \\
\hline 2 & 2 & $\begin{array}{c}2 \\
\text { PROCECO }\end{array}$ & 3 & $30 \times 12$ & $30 \times 16$ & $\begin{array}{l}24 \\
16\end{array}$ & $\begin{array}{l}5 \times 4,10 \times 6 \\
15 \times 16 \\
5 \times 3,10 \times 6 \\
15 \times 7\end{array}$ \\
\hline 3 & 2 & $\begin{array}{c}2 \\
\text { PROCECO }\end{array}$ & 5 & $20 \times 20$ & $20 \times 20$ & 15 & $\begin{array}{l}6 \times 5,4 \times 4, \\
4 \times 5,3 \times 3, \\
3 \times 3 \\
5 \times 4,4 \times 3, \\
4 \times 5,3 \times 4, \\
4 \times 4\end{array}$ \\
\hline 4 & 2 & $\begin{array}{c}2 \\
\text { PROCECO }\end{array}$ & 4 & $20 \times 20$ & $20 \times 20$ & $\begin{array}{l}11 \\
11\end{array}$ & $\begin{array}{l}7 \times 7,6 \times 5 \\
4 \times 5,3 \times 3 \\
7 \times 7,6 \times 5 \\
4 \times 5,3 \times 3\end{array}$ \\
\hline 5 & 3 & $\begin{array}{c}3 \\
\text { PROCECO }\end{array}$ & 4 & $10 \times 20$ & $10 \times 20$ & 0 & $\begin{array}{l}2 \times 5,3 \times 3 \\
2 \times 6,3 \times 6 \\
2 \times 5,3 \times 3 \\
2 \times 6,3 \times 6\end{array}$ \\
\hline
\end{tabular}


Capítulo 4- Coloração e Projeto de Célula de Manufatura

\begin{tabular}{|c|c|c|c|c|c|c|c|}
\hline & Exemplo & Solução & $\begin{array}{l}\text { Número de } \\
\text { células }\end{array}$ & $\begin{array}{l}\text { [peças x tipos } \\
\text { de máquinas] }\end{array}$ & $\begin{array}{c}\text { [peças } \mathrm{x} \\
\text { máquinas] }\end{array}$ & m.i.c. & $\begin{array}{c}\text { Dimensão das } \\
\text { células }\end{array}$ \\
\hline 6 & 4 & $\begin{array}{c}1 \\
\text { PROCECO }\end{array}$ & 3 & $43 \times 16$ & $43 \times 20$ & $\begin{array}{l}0 \\
0\end{array}$ & $\begin{array}{l}16 \times 8,7 \times 4 \\
20 \times 8 \\
16 \times 8,7 \times 4 \\
20 \times 8\end{array}$ \\
\hline 7 & 4 & $\begin{array}{c}1 \\
\text { PROCECO }\end{array}$ & 3 & $43 \times 16$ & $43 \times 19$ & $\begin{array}{l}1 \\
1\end{array}$ & $\begin{array}{l}\text { Não fornecido } \\
13 \times 5,7 \times 4 \text {, } \\
23 \times 10\end{array}$ \\
\hline 8 & 5 & $\begin{array}{c}5 \\
\text { PROCECO }\end{array}$ & 3 & $41 \times 30$ & $41 \times 30$ & $\begin{array}{l}6 \\
6\end{array}$ & $\begin{array}{l}\text { Não fornecido } \\
12 \times 9,10 \times 8 \\
19 \times 13\end{array}$ \\
\hline 9 & 5 & $\begin{array}{c}6 \\
\text { PROCECO }\end{array}$ & 2 & $41 \times 30$ & $41 \times 30$ & $\begin{array}{l}3 \\
3\end{array}$ & $\begin{array}{l}\text { Não fornecido } \\
25 \times 19,16 \times 11\end{array}$ \\
\hline 10 & 2 & $\begin{array}{c}2 \\
\text { PROCECO }\end{array}$ & 3 & $20 \times 12$ & $20 \times 12$ & $\begin{array}{l}0 \\
0\end{array}$ & $\begin{array}{l}6 \times 4,9 \times 5 \\
5 \times 3 \\
6 \times 4,9 \times 5 \\
5 \times 3\end{array}$ \\
\hline 11 & 7 & $\begin{array}{c}7 \\
\text { PROCECO }\end{array}$ & 3 & $10 \times 15$ & $10 \times 15$ & 0 & $\begin{array}{l}4 \times 5,3 \times 5 \\
3 \times 5 \\
4 \times 5,3 \times 5 \\
3 \times 5\end{array}$ \\
\hline 12 & 1 & $\begin{array}{c}1 \\
\text { PROCECO }\end{array}$ & 2 & $7 \times 5$ & $7 \times 7$ & $\begin{array}{l}1 \\
1\end{array}$ & \begin{tabular}{|l}
$4 \times 3,3 \times 4$ \\
$4 \times 3,4 \times 4$
\end{tabular} \\
\hline 13 & 8 & $\begin{array}{c}8 \\
\text { PROCECO }\end{array}$ & 2 & $7 \times 5$ & $7 \times 5$ & $\begin{array}{l}2 \\
2\end{array}$ & $\begin{array}{l}3 \times 2,4 \times 3 \\
3 \times 2,4 \times 3\end{array}$ \\
\hline
\end{tabular}

Tabela 4. 10: Testes realizados 


\begin{tabular}{|c|l|}
\hline $\mathbf{N}^{\mathbf{0}}$ & \multicolumn{1}{|c|}{ Referência } \\
\hline 1 & Meguelati, 1998 \\
\hline 2 & Harhalakis et al., 1990 \\
\hline 3 & Srinivasan et al., 1990 \\
\hline 4 & Burbidge, 1975 \\
\hline 5 & Kumar e Vanelli, 1987 \\
\hline 6 & Wei e Kern, 1989 \\
\hline 7 & Chan e Milner, 1981 \\
\hline 8 & Ballakur e Steudel, 1987 \\
\hline
\end{tabular}

Tabela 4. 11: Exemplos da literatura

Os resultados apresentados na Tabela 4.10 são equivalentes aos resultados descritos $\mathrm{cm}$ Ribeiro e Meguelati (2002). Isso deve-se ao fato do trabalho de Ribeiro e Meguelati (2002) e do trabalho desenvolvido nesta dissertação (PROCECO), duas técnicas de projeto de células de manufatura completamente distintas, terem fornecido os mesmos resultados para os mesmos exemplos da literatura utilizados como testes computacionais.

\subsection{Discussão e Conclusão:}

O algoritmo para auxiliar no projeto de células de manufatura, i. e., o algoritmo de Guénoche com auxilio do algoritmo de Dsatur, apresentou resultados de boa qualidade nos testes realizados com exemplos extraídos da literatura, o que constitui uma perspectiva animadora para a continuidade dos estudos.

$\mathrm{Na}$ implementação realizada é proposta uma maneira de obter a matriz de cargas [peças $\mathrm{x}$ máquinas], computar a dissimilaridade entre as peças fabricadas e projetar as células de manufatura.

O tempo computacional foi irrelevante ou da ordem de segundos para todos os exemplos testados. O programa computacional correspondente ao algoritmo proposto foi escrito em linguagem Delphi e está implementado em um micro-computador Pentium $200 \mathrm{MHz}$ com 64 Kbytes. 
O procedimento adotado para o cálculo da matriz de dissimilaridade foi modificado a partir dos estudos feitos anteriormente por Ferreira (1996) e mostrou-se eficiente nos testes realizados. Nestes testes, foram utilizados os parâmetros $\alpha=1, \beta=0$ e $\gamma=-1$.

O resultado obtido pelo programa depende fortemente dos parâmetros $\alpha, \beta$ e $\gamma$. Dependendo dos valores atribuídos para $\alpha, \beta$ e $\gamma$, pode-se obter uma partição muito boa ou de péssima qualidade.

Outras alternativas de utilização de algoritmos de coloração de grafos para o projeto de células de manufatura que descrevem resultados de boa qualidade na literatura são a busca arborescente por ligações e contrações (Berge, 1970); (Szwarficter, 1983); (Ribeiro e Alves, 1994) e o algoritmo guloso inicializado pelo vértice de maior grau (Gondran e Minoux, 1985). 


\section{Conclusão}

O trabalho realizado nesta dissertação pode ser dividido em três etapas fundamentais:

1 - Estudo dos principais conceitos da Teoria dos Grafos, em particular, de coloração em grafos, dos algoritmos disponíveis na literatura para resolvê-los, dos conceitos da Tecnologia de Grupo e do Projeto de Células de Manufatura.

Realizou-se um estudo do interesse que a aplicação das técnicas da TG e da CM têm para aumentar a produtividade das fábricas que operam na base da produção em lotes pequenos e médios, e/ou sob encomenda. Estas fábricas são responsáveis por $75 \%$ da produção mecânica em países industrializados como o Brasil (Ribeiro e Meguelati, 2002) e o objetivo de aumentar a eficiência das mesmas a partir do emprego de novas organizações é de grande relevância.

2 - Escolha de um algoritmo de coloração em grafos, desenvolvido com o objetivo de resolver o problema de particionamento de um sistema de produção em células de manufatura, para a realização de um estudo mais aprofundado.

A revisão bibliográfica realizada permitiu o levantamento de diversos modelos matemáticos e algoritmos para a resolução do problema. Um grande número de métodos utiliza a computação de um coeficiente de similaridades entre as peças fabricadas e em seguidas fazem uso de técnicas simples de rearranjo de linhas e colunas de um matriz ou de técnicas mais complexas como programação inteira, os sistemas especialistas e a teoria dos grafos.

3 - Implementação computacional do algoritmo selecionado e das modificações introduzidas sobre o mesmo, tendo em vista a aplicação deste na resolução dos problemas, tais como, organizar um sistema de produção em famílias de peças e grupos de máquinas.

O estudo da TG e da CM realizado e apresentado no capítulo 1 desta dissertação, introduz conceitos importantes para a compreensão do problema de particionamento de um sistema de produção em células de manufatura. $O$ estudo da Teoria dos Grafos realizado e apresentado no capítulo 2 introduz conceitos para a compreensão de algoritmos de coloração. Os algoritmos descritos nos capítulos 3 e 4 ressaltam a necessidade e a importância de um estudo teórico mais aprofundado para a proposição e desenvolvimento de algoritmos de particionamento de um sistema de produção em células de manufatura com auxílio de técnicas de coloração em grafos. 
O algoritmo de Guénoche (1993) apresentado no capitulo 3, para particionamento de conjuntos em um número $\mathrm{k}$, fixo, de classes, baseia-se na construção de todas as possíveis colorações de um grafo teto k-colorível. Tendo em vista o caráter NP-Completo do problema tratado (Garey e Johnson, 1979), o autor faz uso de heurísticas para a determinação do teto s, usando heurísticas seqüenciais de coloração, para a obtenção de uma clique, no grafo teto construído e para a coloração efetuada a seguir. Apesar de uso de algoritmos aproximados, Guénoche (1993) descreve resultados de boa qualidade, comprovados pelos testes computacionais, com dados gerados aleatoriamente e com os exemplos da literatura, que realizamos com o PROCECO (Programa para o Projeto de Células por Coloração) .

Um método de coloração em grafos para auxiliar o projeto de células de manufatura foi apresentado no capitulo 4 . O método baseia-se em um procedimento que compreende a computação das dissimilaridades entre as peças e a coloração de um grafo teto, com o objetivo de reunir peças em famílias e as máquinas em subconjuntos, de tal modo que a cada família de peças corresponde um único subconjunto de tipos de máquinas e vice-versa. A solução obtida procura minimizar o número de movimentos inter-células, na medida que procura agrupar as peças com roteiros de fabricação próximos e separar as peças com roteiros diferentes. Foi incorporada uma modificação no cálculo da dissimilaridade entre as peças, onde o usuário entra com os parâmetros. Esta forma é mais flexível e permite ao usuário modificar os parâmetros várias vezes com o objetivo de obter uma boa solução de maior qualidade.

Os exemplos tratados mostram a eficiência do método, tanto na qualidade das soluções obtidas (reduziu-se o número de movimentos inter-células em 3 casos extraídos da literatura), quanto em tempo computacional (inferior a um minuto para todos os exemplos testados) ou em ocupação do espaço da memória da máquina, o que torna, portanto, acessível a um grande número de indústrias, principalmente aquelas de porte pequeno e médio.

O programa computacional correspondente ao método proposto foi escrito em linguagem Delphi e está implementado em microcomputador Pentium $200 \mathrm{MHz}$ com 64 Mbytes.

$\mathrm{O}$ método desenvolvido, o programa computacional codificado e os testes realizados proporcionaram a submissão e aceitação deste trabalho para publicação no II COBEF - Congresso Brasileiro de Engenharia de Fabricação que acontecerá em Uberlândia, MG, em maio de 2003.

Entre as tarefas a executar, como continuidade do trabalho apresentado, destacam-se:

- Reestudo de procedimentos específicos empregados no método de coloração de Guénoche (1993) com o objetivo de substituí-los por rotinas mais eficientes. 
- Continuação do levantamento bibliográfico realizado, consultando outras áreas que também tem se dedicado ao estudo do projeto de células de manufatura, tais como: algoritmos genéticos, conjuntos nebulosos, redes neurais, simulated annealing, busca tabu e outras.

- Realização de testes computacionais para exemplos reais de grande porte com o objetivo de avaliar o tempo de cálculo, a utilização de memória e a qualidade das soluções obtidas.

- Implementação do método proposto nesta dissertação na forma de um sistema especialista, fazendo-se uso de conhecimentos específicos de dificil modelamento. 


\section{Referências Bibliográficas:}

- Adil, G. K., Rajanani, D., Strong, D., 1997, “Assignment Allocation and Simulated Annealing Algorithms for Cell Formation", IlE Transactions, 29, pp. 53-67.

- Appel, K. I., Haken, W., 1976, "The Solution to the Four-color-map Problem", Scientific American, n. 108.

- Arruda, P. E. S., Vila Fo., E. G., 1994, "Levantamento do Estágio Atual de Implementação da Tecnologia de Grupo e Células de Manufatura do Estado de São Paulo", XV ENEGIP/IICIE, pp. 1559-1562.

- Askin, R. G., Huang Yuanshu, 2001, "Forming Effective Worker Teams for Cellular Manufacturing", Int. J. of Prod. Res., 39, 11, pp. 2431-2451.

- Ballakur, A., Steudel, H. J., 1987, “A Within Cell Based Heuridtic for Designing Cellular Manufacturing Systems”, Int. J. of Prod. Res., 5, pp. 639-665.

- Berge, C., 1970, “Graphes”, Ed. Gauthier-Villars.

- Berge, C., 1976, "Graphs and Hypergraphs”, North-Holland Publishing Company.

- Boctor, F. F., 1991, "A Linear Formulation of the Machine-Part Cell Formation Problem", Int. J. of Prod. Res., 29, pp. 343-356.

- Boctor, F. F., 1996,'The Minimum Cost, Machine-Part Cell Formation Problem", Int. J. of Prod Res., 34, pp. 1045-1063.

- Brélaz, D., 1979, "New Methods to Color the Vertices of am Graph", Comm. Of the ACM, 22, pp. 251-256.

- Brown, J. R., 1972, "Chromatic Scheduling and the Chromatic Number Problem", Management Science, 19, pp. 456-463.

- Brown, E. C., Sumichrast, R. T., 2001, "CF_GGA: A Grouping Genetic Algorithm for Cell Formation Problem", Int. J. of Prod. Res., 39, 16, pp. 3651-3669.

- Burbidge, J. L., 1975, "The Introduction of Group Technology", Ed. John Willey.

- Chan, H. M., Milner, D. A., 1981, "Direct Cluster Algorithm for Group Formation in Cellular Manufacture", J. of Manufacturing Systems, 1, pp. 235-242.

- Chu, C. H., Hayya, J. C., 1991, “A Fuzzy Clustering Approach to Manufacturing Cell Formation”, Int. Industrial Engineering Conference, Orlando F L USA, pp. 495-500.

- De Werra, D., 1985, "Na Introduction to Timetabling European Journal of Operational Research", EJOR 19, pp. 151-162. 
- De Werra, D., 1990, "Heuristics for Graph Coloring", Computing Supplementum, 7, pp. 191-208.

- Deutsch, S. J., Freeman, S. F., Helander, M., 1998, "Manufacturing Cell Formation Using an Improved p-Median Model", Computers and Industrial Engineering, 34, 135146.

- Dimopoulos, C., Mort, N., 2001, "A Hierarchical Clustering Methodology Based on Genetic Programming for the Solution of Simple Cell-Formation Problems", Int. J. of Prod. Res., 39, 1, pp. 1-19.

- Doumeingts, G., 1984, "La Production Assistée par Ordinateur", Bulletin de Recherche en Informatique et Automatique.

- Ferreira, R. C., 1996, "Uma Aplicação de Coloração em Grafos para a Tecnologia de Grupo", Dissertação de Mestrado USP/ICMC/SCE.

- Ferreira, M. S., Resende, M. , 1995, "Um Exame à Prática do Controle de Produção em Células de Manufatura", XV ENEGIP/IICIE, pp. 1579-1583.

- Garey, M. R., Johnson, D.S., 1979, “Computers and Intractability”, Ed. Freeman.

- Gondran, M., Minoux, M., 1990, “Graphs and Algorithms”, Ed. John Wiley \& Sons.

- Gondran, M., Minoux, M., 1985, “Graphes et Algorithmes”, Ed. Eyrolles.

- Gouvêa, E. F., 1993, "Contribuições às Heurísticas do Problema de Coloração em Grafos", Dissertação de Mestrado IME/ES.

- Guénoche, A., 1993, "Énumération des Partitions de Diamètre Minimum", Discrete Mathematics, 111, pp. 227-287.

- Hansen, P., DeLattre, M., 1978, "Complete-Link Cluster Analysis by Graph Coloring”, J. Am. Stat. Ass., 73, pp. 397-403.

- Hansen, P., Jaumard, B., 1987, "Minimum Sum of Diameters Clustering", J. of Classification, 4, 2, pp. 215-226.

- Harhalakis, G., Nagi, R. and Proth, J. M., 1990, "An Efficient Heuristic in Manufacturing Cell Formation for Group Technology Applications”, Int. J. of Production Research, 28, pp. 185-198.

- Heawood, P. J., 1890, "Map-Color Theorems”, Quart. J. Math., v. 24, pp. 332-338.

- Hyer, N. L., Wemmerlöw, U., 1989, "Group Technology in the US Manufacturing Industry: A Survey of Current Practices”, Int. J. Prod. Res., 27, 8, pp. 1287-1304.

- Hubert, L. J., 1974, "Spanning Trees and Aspects of Clustering”, Brit. J. Math. Stat. Psy., 27, pp. 14-28. 
- Johnson, D. S., 1974, "Worst Case Behavior of Graph Coloring Algorithms", Proc. $5^{\text {th }}$ s. ed. Conf. Combinatorics, Graph Theory and Computing, pp. 513-527.

- Karchmer, M., Naor, J., 1988, “A Fast Parallel Algorithm to Color a Graph with p Colors", J. of Algorithms, 9, pp. 83-91.

- Kumar, K. R., Vanelli, A., 1987, "Strategic Subcontracting for Efficient Disaggregated Manufacturing”, Int. J. of Prod. Res., 25, pp. 1715-1728.

- Kusiak, A., 1987, “The Generalized Group Technology Concept”, Int. J. of Prod. Res., 25, pp. 561-569.

- Kusiak, A., 1988, "EXGT-S: A Knowledge Based System for Group Technology", Int. J. of Prod. Res., 26, 5, pp. 887-904.

- Kusiak, A., Chow, W. S., 1988, “Decomposition of Manufacturing Systems”, IEEE Journal of Robotics and Automation, 4, 5, pp. 457-471.

- Kusiak, A., Chung, Y., 1991, "GT/ART: Using Neural Networks to Form Machine Cells", Manufacturing Review, 4, pp. 293-301.

- Leclerc, B., 1986, "Caractérisation, Construction et Dénombrement des Ultramétriques Supérieures Minimales", Statistiques el Analyse des Dones, 11, 2, pp. 26-50.

- Lee, H., Malave, C. O., Ramachandran, S., 1992, "Neural Network-based Design of Cellular Manufacturing Systems”, Journal of Inteligent Manufacturing, 3, pp. 325-332.

- Leighton, F. T., 1979, “A Graph Coloring Algorithm for Large Scheduling Problems”, J. Res. Nath. Bur. Standards, v. 84, pp. 486-506.

- Liao, T. W., 1994, "Design of Line-Type Cellular Manufacturing Systems for Minimum Operating and Material Handling Costs", Int. J. of Prod. Res., 32, pp. 387-397.

- Mahdavi, 1., Kaushal, O. P., Chandra, M., 2001, "Graph-neural Network Approach in Cellular Manufacturing on the Basis of a Binary System", Int. J. of Prod. Res., 39, 13, pp. 2913-2922.

- Mahmoodi, F., Dooley, K. J., Starr, P. J., 1990, “An Investigation of Dynamic Group Scheduling Heuristics in a Job Shop Maufacturing Cell", Int. J. of Prod. Res., 9, pp. 1695-1711.

- Meguelati, S., 1988, "Méthodes de Classification Pour la Constituion D’llots de Fabrication et L'Ordonnancement", Thése de Dostorat Insat, France.

- Meguelati, S., 1998, "Méthodes de Classification pour la Constituion D'llots de Fabrication”, Rapport LAAS 98175, França. 
- Mitrofanov, S. P., 1959, "The Scientific Principles of Group Technology”, National Lending, Ed. Library London.

- Moon, Y. B., Chi, S. C., 1992, "Generalized Part Family Formation Using Neural Network Techniques", Journal of Manufacturing Systems, 11, pp. 149-159.

- Netto, P.O.B, 1979, "Teoria e Modelos de Grafos", Ed. Edgard Blücher.

- Oliveira, M. M. B., Giraldi, J. M. E., Costa, A. L., Ribeiro, J. F. F., 1999, "Manufacturing Cells - The Case of na Implements Factory for Sugar Cane", $15^{\text {th }}$ IFORS, Pequim, China, anais em CD-ROM.

- Opsut, R. J., Roberts, F. S., 1981, "On the Fleet Maintenance, Mobile Radio Frequency, Task Assignment and Traffic Phasing Problems", Em: Chartrand, G. et al., "The Theory and Applications of Graphs", John Wiley \& Sons.

- Prins, C., 1997, “Algorithmes de Graphes", Ed. Eyrolles.

- Qattani-al, I., 1990, "Designing Flexible Manufacturing Cells Using a Banch and Bound Meted", Int. J. of Prod. Res., 28, pp. 325-336.

- Ramabhatta, V., Nagi, R., 1998, "An Integrated Formulation of Manufacturing Cell Formation with Capacity Planning and Multiple Routings", Annals of Operations Research, 77, pp. 79-95.

- Rao, M. R., 1971, "Cluster Analysis and Mathematical Programming”, J. Am. Stat. Ass., 66, pp. 622-626.

- Ribeiro, J. F. F., 1991, "Constitution d'Ilots et Ordonnancement dans um Atelier de Production", Tese de DoutoradoLAAS/INSA, Toulouse, França.

- Ribeiro, J. F. F., Alves, M. R. P. A., 1994, "Projeto de Células de Manufatura por meio de Ligações-Contrações", XV CILAMCE, Belo Horizonte, MG, pp. 1470-1476.

- Ribeiro, J. F. F., Meguelati, S., 2002, "Organização de um Sistema de Produção em Células de Manufatura", Gestão \& Produção, v.9, n.1, pp. 62-77.

- Ribeiro, J. F. F., Pradin, B., 1993, “A Methodology for Cellular Manufacturing Design”, International Journal of Production Research, ISSN 0020-7543, Ed. Taylor \& Francis, 31,1, pp. 235-250.

- Ribeiro, J. F. F., Ribeiro, C. M., 1993, "Um Algoritmo de Coloração em Grafos para o Projeto de Células de Manufatura”, XIV CILAMCE, São Paulo, SP, pp. 898-903.

- Sakarovitch, M., 1984, "Optimisation Combinatorie" (2 volumes), Ed. Hermann.

- Santos, L. M. R., 1996, "Uma Abordagem de Particionamento de Conjuntos através de Coloração em Grafos”, Dissertação de Mestrado USP/ICMC/SCE. 
- Shafer, S. M., Kern, G. M., 1992, “A Mathematical Programming Approach for Dealing with Exceptional Elements in Cellular Manufacturing”, Int. J. of Prod. Res., 30, pp. 1029-1036.

- Sing, N., 1993, "Design of Cellular Manufacturing Systems: An Invited Review", European Journal of Operation Research, 69, pp. 284-291.

- Slack, Nigel et al., 1997, “Administração da produção”, São Paulo, Atlas.

- Sofianopoulou, S., 1999, "Manufacturing Cell Design with Alternative Process Plans and/or Replicate Machines", Int. J. of Prod. Res., 37, pp. 707-720.

- Srinivasan, G., Naredran, T. T. and Mahavedan, B., 1990, “An Assignment Model for the Part-families Problem in Group Technology", Int. J. of Prod. Res., 28, pp. 145-152.

- Szwarcfiter, J. L., 1983, “Grafos e Algoritmos Computacionais”, Ed. Campus.

- Venugopal, V, Narendran, R. T., 1992, “Cell Formation in Manufacturing Systems Through Simulated Annealing an Experimental Evaluation", European J. of. Operation Research, 63, pp. 409-422.

- Venugopal, V, Narendran, R. T., 1992a, "A Genetic Algorithm Approach to the Machine-Component Grouping Problem with Multiple Objectives", "Computers and Industrial Engineering, 22, pp.469-480.

- Viswanathan, S., 1995, "Configuring Cellular Manufacturing Systems: A Quadratic Integer Programming Formulation and a Simple Interchange Heuristic”, Int. J. of Prod. Res., 33, pp. 361-376.

- Waghodekar, P. H., Sahu, S., 1984, "Machine-component Cell Formation in Group Technology: MACE”, Int. J. Prod. Res., 22, 6, pp. 937-948.

- Wei, J. C. and Kern, G. M., 1989, "Commonality Analysis: A Linear Cell Clustering Algorithm for Group Technology”, Int. J. of Prod. Res., 12, pp. 2053-2062.

- Welsh, D. J. A., Powell, M. B., 1967, “An Upper Bound for Chromatic Number of a Graph and its Application to Timetabling Problems", Computing Journal, 10, pp. 85-96.

- Won, Y., 2000, “Two-Phase Approach to GT Cell Formation Using Efficent p-Median Formulations", Int. J. of Prod. Res., 38, 7, pp. 1601-1613.

- Xu, H., Wang, H. P., 1989, "Part Family Formation for Group Technology Applications Based on Fuzzy Mathematics”, Int. J. of Prod. Res., 27, pp. 1637-1651.

- Zhao, C., Wu, Z., 2000, "A Genetic Algorithm for Manufacturing Cell Formation with Multiple Routes and Multiple Objectives”, Int. J. Prod. Res., 38, 2, pp. 385-395. 